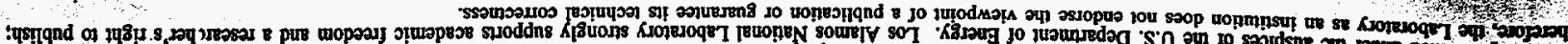

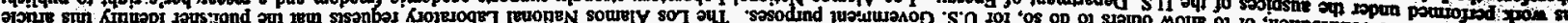

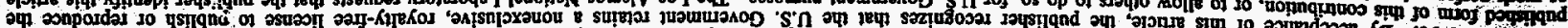

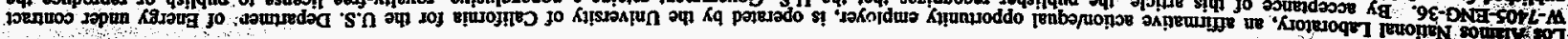

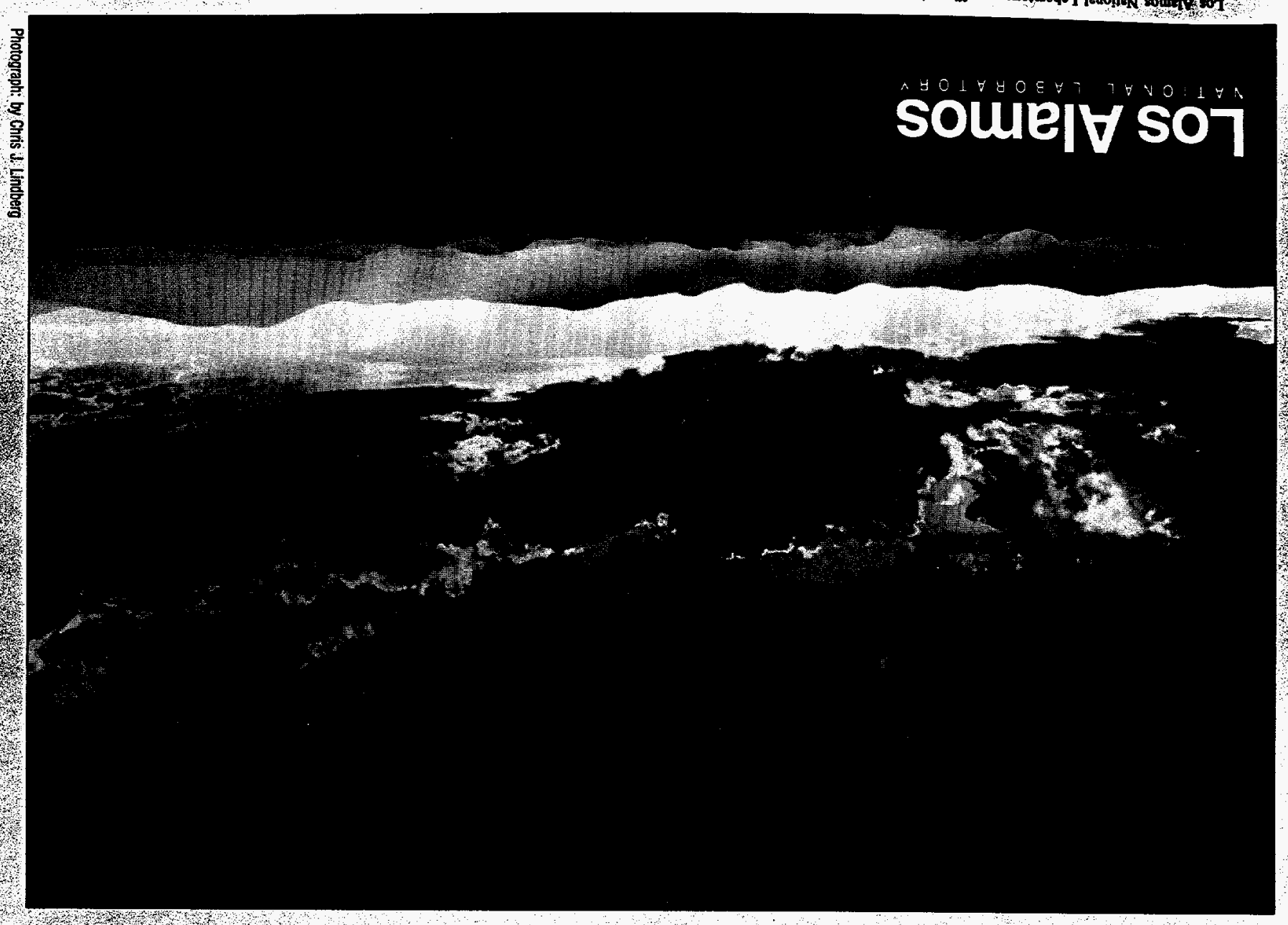

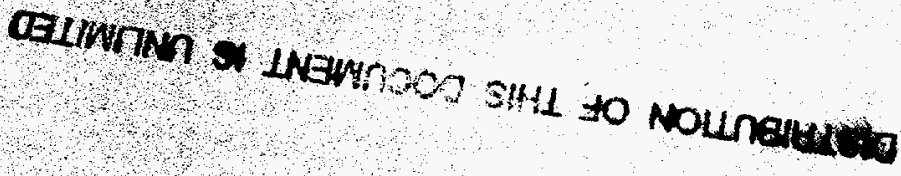

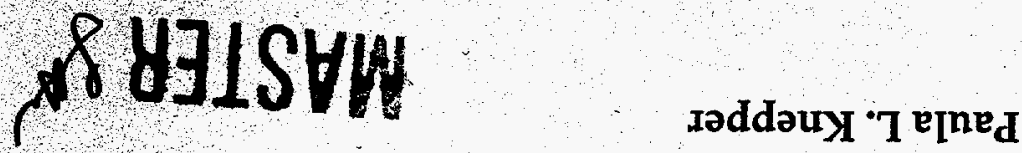

Sq

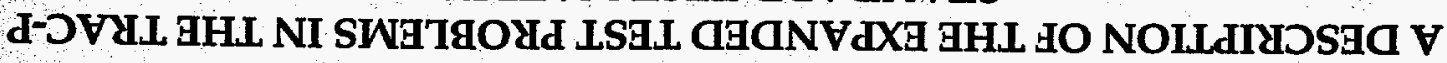




\title{
A DESCRIPTION OF THE EXPANDED TEST PROBLEMS \\ IN THE TRAC-P STANDARD TEST MATRIX
}

\author{
Paula L. Knepper \\ Los Alamos National Laboratory \\ Technology and Safety Assessment Division \\ Los Alamos, New Mexico 87545
}

February 20, 1998

\author{
Prepared for the \\ Division of Systems Technology \\ Office of Nuclear Regulatory Research \\ US Nuclear Regulatory Commission \\ Washington, DC 20555
}




\section{DISCLAIMER}

This report was prepared as an account of work sponsored by an agency of the United States Government. Neither the United States Government nor any agency thereof, nor any of their employees, makes any warranty, express or implied, or assumes any legal liability or responsibility for the accuracy, completeness, or usefulness of any information, apparatus, product, or process disclosed, or represents that its use would not infringe privately owned rights. Reference herein to any specific commercial product, process, or service by trade name, trademark, manufacturer, or otherwise does not necessarily constitute or imply its endorsement, recommendation, or favoring by the United States Government or any agency thereof. The views and opinions of authors expressed herein do not necessarily state or reflect those of the United States Government or any agency thereof. 


\section{DISCLAIMER}

Portions of this document may be illegible electronic image products. Images are produced from the best available original document. 


\title{
A DESCRIPTION OF THE EXPANDED TEST PROBLEMS IN THE TRAC-P STANDARD TEST MATRIX
}

\begin{abstract}
This report describes the expanded set of test problems that were created to augment the existing Transient Reactor Analysis Code (TRAC)-P standard matrix of test problems. The expanded test problems were created to support the TRAC-P modernization effort. In most cases, these test problems were modified or expanded versions of problems in the TRAC Standard Test Matrix. A problem description is included for each problem added to the Standard Test Matrix. In this description, the details regarding modifications of the original test problem are included, as well as the observed problem results. This expanded test set will be used to verify that the predicted results for the modernized version of TRAC-M/f90 are "null" relative to the archival version of TRAC-P/MOD2 (Ver. 5.4.25), the latter being the base version on which work on the modernized code began. The problems described in this document increase the percentage of executable source coding that is activated when the Standard Test Matrix is run from $71 \%$ to $83.5 \%$. A brief review of the characteristics of the portions of the source code that are not activated when running the expanded Standard Test Set also is provided. With a few exceptions, we have concluded that the cost to increase the fraction of coding activated by the Standard Test Set further is high relative to the increased coverage that can be attained. Therefore, we recommend that this activity be concluded.
\end{abstract}

\section{INTRODUCTION}

To support the modernization effort for the pressurized water reactor (PWR) version of the Transient Reactor Analysis Code (TRAC)-P, the TRAC-P Standard Test Matrix has been expanded. The current Standard Test Matrix contains 42 problems that are described in Ref. 1. A primary use of the current Standard Test Matrix is to verify that the results predicted by the modernized Fortran90 (f90) TRAC (TRAC-M/f90) are "null" relative to TRAC-P/MOD2, Ver. 5.4.25, the base code from which the TRAC-M/ 990 derives. The results of the base and modernized code are declared to be null if the predicted results are identical. The null success metric is the primary success metric for modernization of TRAC-P. If the null success metric is to be meaningful, the test problems used to determine nullness must activate a high percentage of the lines of source code in both TRAC-P/MOD2, Ver. 5.4.25 and TRAC$\mathrm{M} / \mathrm{f} 90$. 
As we began the enhancement of the Standard Test Matrix, $71 \%$ of the executable lines of source coding in TRAC-P/MOD2, Ver. 5.4 .25 were activated collectively by the problems in the Standard Test Matrix. This was deemed to be inadequate coverage of TRAC-P/MOD2, Ver. 5.4.25 for validating, i.e., null testing, the modernized code. Therefore, an effort was made to expand the problem set in the Standard Test Matrix to provide increased null testing.

PureCoverage ${ }^{\odot}$ software was used to determine the lines of coding exercised by the Standard Test Matrix and the expanded test matrix. PureCoverage is a software development tool that provides coverage statistics, i.e., lines of coding exercised on a subroutine basis and a line-by-line basis. This is a test coverage product intended to aid in code development and testing. PureCoverage provides some valuable information, ${ }^{2}$ such as

1. identifying portions of coding that tests have not exercised,

2. accumulating coverage data over multiple runs, and

3. merging data from different programs sharing a common source code.

PureCoverage was used to identify areas in the code where further assessment was necessary. With study, important deficiencies that have been identified are code input options associated with unexercised coding, code bugs, dead coding, and unsupported coding.

We began with the Standard Test Matrix described in Ref. 1 . This standard test set then was expanded to exercise the coding further in TRAC-P/MOD2, Ver. 5.4.25. Additional problems were created by modifying the current Standard Test Matrix or adding to the test set input decks created previously for other analyses.

This document is divided into four sections. The first section describes the expanded test matrix. The second section describes areas of the code where code bugs and dead coding were discovered. The next section lists coding that is no longer supported. We conclude with the characteristics of the remaining portions of the code, which are not tested by the expanded Standard Test Matrix.

\section{PROBLEM DESCRIPTION}

The following is the list of problems added to the test set. These problems were created for other analytical or code development efforts at Los Alamos National Laboratory (LANL) but were not included in the Standard Test Matrix. We have determined that these problems increase the coverage of the code by exercising previously unexercised coding. We recommend that these problems be added to the Standard Test Matrix.

- short and long problem sets in English units (ptracc.units and ptraccl.units);

- radiation problems (tracinG and tracinH); 


\section{LA-UR-98-959}

- LOFTK (loftk and loftkr);

- AP600 (sbinss.14, sbintr200, and sgcasea);

- D2O problem (mss2.d2o);

- ZIONPWR modified;

- FLECHT-SEASET;

- CCTF (cctf14 and cctf54);

- Akimoto (inmist.new, inplug.new, and intrans.new);

- H. B. Robinson (inrenode.61); and

- FXKILL ( errinopts, errinteger, erreal, errcomma, errcomment, errelev, errduelev, errcont, errend, errfill, errrepeat, and errrepeat1).

A description of each of these problems follows.

\subsection{Short and Long Problem Sets in English Units}

The short and long problem sets in English units comprised the following problems. The problems in the short problem set are drain, hcond1, hcond2, hcond3, hcond4, hcond5, marvik, mscl, mscv, msp2, mspl, mspv, msr2, msrl, msrv, mss2, mssl, mssv, mst2, mstl, mstv, msv2, msvv, rod2, tindwn, tinup, utube, ZIONPWR, w4loopn, and w4loopnr. For a detailed description of these problems, see Ref. 1. However, the problems differ from those described in Ref. 1 because these problems exercise the English unit option for iogrf, iolab, and ioout in the namelist. The long problem set in English units is made up of loft126n and loft126rn. For a complete description of these problems, see Ref. 1; the only modification to these problem descriptions is the use of the English unit option for the outputs in the trcgrf, trcout, and trcmsg files.

\subsection{Radiation Test Problems}

The radiation test problems $\mathrm{G}$ and $\mathrm{H}$ were used to test the radiation enclosure model. ${ }^{3}$ These problems were created to test the implementation of the radiation heat-transfer model into TRAC-P/MOD2. A total of nine problems for code verification are described in detail in Ref. 3. Problems $G$ and $H$ test the effects of convection, and a participating medium is included.

In problem $G$ there are two enclosures formed by three concentric cylinders. The participating medium is steam at $1 \mathrm{~atm}$ and $373.15 \mathrm{~K}$. This problem was added to the expanded test matrix because it exercises subroutines "sfa22v" and "ssl22v". The upper-level tree diagram of subroutines added for the radiation enclosure model is 
shown on page 15 of Ref. 3 and includes radems, radmap, radfp, radsol, radchyd, and radchts. These subroutines are exercised by all of the radiation test problems.

Problem $\mathrm{H}$ consists of four surfaces of an enclosure that is infinitely long and has a square cross section. The participating medium again is steam at $1 \mathrm{~atm}$ and $373.15 \mathrm{~K}$. Problem $\mathrm{H}$ was included in the expanded test set because it exercises subroutines "sfa44a" and "ssl44a".

The remaining seven problems were not added to the expanded test problem set because they do not expand the coverage of TRAC-P/MOD2. These problems exercise the upper-level subroutines shown on page 15 of Ref. 3 but do not improve the code coverage.

\subsection{AP600 Plant Models}

The problems sbinss.14 and sbintr200 are two-theta core Westinghouse AP600 PWR plant models. These decks test small-break (SB) loss-of-coolant-accidents (LOCAs) and intermediate-break (IB) LOCAs. Problem sbinss.14 is a steady-state test, whereas sbintr200 is a combined transient restart model for the SBLOCA.

The sgcasea is a stand-alone AP-600 steam generator model that uses the timedependent fill boundary option. In the standard problem matrix, the table input was not exercised in numerous components. The coding for reading the table input was repeated in numerous components, and this problem inputs the fill boundary tables in the form of a control block.

\subsection{Heavy-Water Coolant Model}

The problem mss2.d2o uses heavy-water fluid properties, which are initiated in the input deck by selecting id20 $=1$. This input deck consists of three components: two breaks and a pipe. The pipe is made up of 22 cells and is a mirror image, with a pressure boundary condition on each end.

Numerous TRAC-P/MOD2 subroutines are used specifically for an analysis with heavy water. Without this problem, the following subroutines are not exercised: thermd, seteod, viscvd, fpropd, rholid, sattmd, cpvv1d, satded, satprd, labeld, thcld, viscld, and cplld. These subroutines account for 454 lines of coding, and adding the mss $2 . d 20$ problem exercises $65 \%$ of the heavy-water-related lines of coding.

\subsection{ZIONPWR Modified Problem}

A modified ZIONPWR input deck named ZIONPWRN is similar to the ZIONPWR included in the Standard Test Matrix. ${ }^{1}$ The ZIONPWRN deck is a Zion PWR core containing a simple pump and valve model. For further details regarding the ZIONPWRN input deck, see Section 2.10 of Ref. 1. The significant difference between this deck and the deck in the Standard Test Matrix is the expansion of the control system. In this problem, the Zion PWR plant model is used to test all aspects of the control-system signal variables, control blocks, and trips. There are 132 control 


\section{LA-UR-98-959}

blocks added to the ZIONPWR standard test problem to evaluate 66 different control-block operations and to evaluate both the user-specified and internal TRAC-P/MOD2 initialization procedures. ${ }^{1}$ There are an additional nine trips that test all trip-related features one or more times. The control-procedure signal variables and control blocks are in this test problem for the purpose of testing whether they are initialized and evaluated correctly. This problem improves the coverage of the conblk subroutine significantly by exercising an additional 200 lines of coding.

\subsection{FLECHT-SEASET}

The Full-Length Emergency Cooling Heat Transfer-Separate Effects and Systems Effects Test (FLECHT-SEASET) is a forced reflood for a $17 \times 17$ unblocked rod bundle. ${ }^{4}$ The test number for the FLECHT-SEASET problem is 31504. The FLECHTSEASET problem exercises coding that models the reflood heat-transfer process.

\section{7. $\mathrm{CCTF}$}

Two problems, run 14 and run 54, have been added to the expanded test matrix from the Cylindrical Core Test Facility (CCTF) and are integral effect test problems. ${ }^{5}$ These problems are multiple tests of refill and reflood phases of LBLOCAs. ${ }^{4}$

The cctf14 problem is from the CCTF run 14 reflood case. The model in this input deck consist of six components, which include a fill, inlet pipe, vessel, outlet pipe, break, and heat structure. The vessel is one dimensional (1D).

The cctf54 problem was used for the analysis of the CCTF run 54. In this problem, there is a vessel nodalized into 2 azimuthal zones, 4 radial rings, and 16 axial levels. This deck is a two-loop model, where one of the loops is broken and each loop consists of a vessel, steam generator, and emergency core cooling (ECC) injection.

\subsection{AKIMOTO Test Problems}

Inmist.new, inplug.new, and intrans.new are models of the Akimoto Test Facility. At this facility, the condensation of steam on subcooled water in a horizontal test section of a rectangular cross section was studied. ${ }^{6}$ The inmist.new problem tests the TRAC-P condensation model, ${ }^{5}$ which predicts the rate of condensation for mist flow regimes. The problem inplug.new models a plug of water in a horizontal channel. The intrans.new problem examines the flow rate in a stable flow region; as the flow rate is increased, the flow starts to show oscillations. This models the oscillatory flow that occurs during the transition. The input decks for these three problems are modeled with two tee components, one for the test section and one modeling the outlet tank, a break, and three fill components. These three input decks were created by LANL for the Akimoto Condensation Experiments and are described further in Ref. 6. 


\subsection{H. B. ROBINSON MODEL}

Inrenode.61 is a coarsely noded H. B. Robinson plant model, which consists of a twodimensional (2D) reactor vessel. In the vessel there are two heat structures, a powered rod and an unpowered slab. The key feature of this model is the use of twophase homologous pump curves. This problem further exercises the pump component.

\subsection{FXKILL Update Test Problems}

The input decks errinopts, errinteger, erreal, errcomma, errcomment, errelev, errduelev, errcont, errend, errfill, errrepeat, and errrepeat1 were created to test for user input errors. These problems can be used only when the update fxkill is added to the archival code. Table 1 lists the problem names, input error, and results.

\subsection{Modified Test Problems}

To exercise the code further, the problems in the standard matrix and those described in Sections 2.1 to 2.10 have been modified slightly. Areas of the code that have not been tested sufficiently include the decay models, invalid or inconsistent user input, the heat-structure and vessel components, and table inputs. The following problems were created from one of the Standard Test Matrix problems or from one of the problems described above. The base deck is specified, and the changes to the deck are noted in the explanation of the problem.

The subroutine "namlst" performs input data checks on all of the namelist variables. This subroutine contained 511 lines of untested coding after running the standard test problems. To test this section of coding, a few problems were created with intentional namelist errors. There are 7 problems that improve the coverage of the "namlst", subroutine from $25 \%$ to $86 \%$, or over 400 lines of coding. These problems exercise the error messages that correspond to improper input in the namelist. A description of the problems, including the errors introduced and the warning messages, is shown in Table 2 . For each invalid namelist input, an out-ofrange value output is produced as a warning message shown in column three of Table 2.

These problems represent simple tests. A large portion of the unexercised TRACPF1/MOD2 is from unexercised warning messages, which are displayed and exercised when a user inputs invalid or inconsistent data. In some cases we have tried to exercise this coding, but overall, this coding makes up the majority of the still unexercised coding.

The subroutine "decay" was not exercised by the original test problems. A few problems were created to exercise this subroutine. Table 3 lists the decay problems and the options selected for the each problem. A problem that uses the ANS-79 decay-heat standard and a problem using the ANS-79 decay-heat standard with heavy element decay were created. ${ }^{7}$ When these input decks were run, the decay 
TABLE 1

FXKILL ERROR-CHECKING DECKS

\begin{tabular}{|c|c|c|}
\hline Problem Name & Input Options & Results \\
\hline errinopts & $\begin{array}{l}\text { Misspelled namelist variable } \\
\text { ikfac }\end{array}$ & $\begin{array}{l}\text { Incorrect variable name: } \\
\text { core dump }\end{array}$ \\
\hline errinteger & $\begin{array}{l}\text { Main data card-4 "stdyst" was } \\
\text { input as real instead of } \\
\text { integer }\end{array}$ & Error not detected \\
\hline erreal & $\begin{array}{l}\text { Main data card-5 "epso" was } \\
\text { input as integer instead of } \\
\text { real }\end{array}$ & Error not detected \\
\hline errcomma & $\begin{array}{l}\text { Heat-transfer coefficient on } \\
\text { pipe component was input as } \\
0,0 \text { not } 0.0\end{array}$ & $\begin{array}{l}{ }^{*} \text { preinp* input error detected } \\
\text { in tracin. card number } 127\end{array}$ \\
\hline errcomment & $\begin{array}{l}\text { On main-cell array "vol" } \\
\text { used vol }{ }^{*}, \text { not }^{*} \text { vol }{ }^{*}\end{array}$ & $\begin{array}{l}\text { "preinp* input error detected } \\
\text { in tracin. card no. } 139,{ }^{*} \text { load* } \\
\text { input error detected, rest of } \\
\text { input skipped }\end{array}$ \\
\hline errelev & $\begin{array}{l}\text { On FILL entered } 6.0 \text { instead of } \\
7.0 \text { for "felv" }\end{array}$ & $\begin{array}{l}\text { No error found on reading } \\
\text { input, but trcout shows felv }= \\
6.0 \text { and grav }=2.0 \text { (should be } \\
1.0 \text { ) }\end{array}$ \\
\hline errduelev & $\begin{array}{l}\text { On FILL entered } 8.0 \text { instead of } \\
7.0 \text { for "felv" (same as cell-1, } \\
\text { Pipe) }\end{array}$ & $\begin{array}{l}\text { No error found on reading } \\
\text { input, but trcout shows felv }= \\
8.0 \text { and grav }=0.0 \text { on cell- } 1 \\
\text { Pipe (should be } 1.0 \text { ) }\end{array}$ \\
\hline errcont & $\begin{array}{l}\text { On ARRAY entered " } \mathrm{c} \text { " } \\
\text { instead of "s" for } \\
\text { continuation line }\end{array}$ & $\begin{array}{l}\text { *preinp* input error detected } \\
\text { in tracin. card number } 142\end{array}$ \\
\hline errend & $\begin{array}{l}\text { On ARRAY info line did not } \\
\text { input an "e" to indicate "end } \\
\text { of array" }\end{array}$ & $\begin{array}{l}\text { No differences, TRAC did not } \\
\text { catch error }\end{array}$ \\
\hline errfill & $\begin{array}{l}\text { On ARRAY info line input } 2 \\
\text { " } \mathrm{f} \text { " instead of } 1 \text { to indicate } \\
\text { "fill array" }\end{array}$ & $\begin{array}{l}\text { No differences, TRAC did not } \\
\text { catch error }\end{array}$ \\
\hline errrepeat & $\begin{array}{l}\text { On ARRAY info line input } \\
\text { less values then were needed }\end{array}$ & Error was not detected \\
\hline errrepeat1 & $\begin{array}{l}\text { On ARRAY info line input } 2 \\
\text { "r" instead of } 1 \text { to indicate } \\
\text { "repeat values" }\end{array}$ & $\begin{array}{l}\text { *preinp* input error detected } \\
\text { in tracin. card number } 141 \\
\text { rest of component skipped }\end{array}$ \\
\hline
\end{tabular}


TABLE 2

NAMELIST WARNING MESSAGE PROBLEMS

\begin{tabular}{|c|c|c|}
\hline Problem Name & Input Options & Results \\
\hline namelist.a & $\begin{array}{l}\text { - } \text { istopt, fdfhl, icflow = } 3 \\
\text { - } \text { dtstrt }=-2.0 \\
\text { - } \text { iadded, icdelt, }=-1 \\
\text { - } \text { idiag, igas = 5 } \\
\text { - iconht, idiags, ielv, ieeeg }=2 \\
\text { - invan }=1\end{array}$ & $\begin{array}{l}\text { Warning message for each } \\
\text { of the variables } \\
\text { - *namlst* variable has out- } \\
\text { of-range value }\end{array}$ \\
\hline namelist.b & $\begin{array}{l}\text { - } \text { istopt }=1 \\
\text { - } \text { alp }=3\end{array}$ & $\begin{array}{l}\text { - Warning message } \\
\text { - *namlst variable has out- } \\
\text { of-range value }\end{array}$ \\
\hline namelist.c & $\begin{array}{ll}\text { - } & \text { htcwl }=-1.0 \\
\text { - } & \text { iconht }=1\end{array}$ & $\begin{array}{l}\text { - Warning message } \\
\text { - }{ }^{*} \text { namlst* variable has out- } \\
\text { of-range value }\end{array}$ \\
\hline namelist.d & $\begin{array}{l}\text { - cfz3, hd3, hstn, qppp, tw, } \\
\text { htcwv = -1.0 } \\
\text { - igeom3, iofftk, ikfac, iogrf, } \\
\text { ioinp, iolab, ipowr = 2 } \\
\text { - iblaus, nfrc1, nfrc3, nifsh = } 3 \\
\text { - imfr, ihor, inlab }=4\end{array}$ & $\begin{array}{l}\text { - Warning message } \\
\text { - *namlst* variable has out- } \\
\text { of-range value }\end{array}$ \\
\hline namelist.e & $\begin{array}{l}\text { - ioout, ireset, isolcn, isscvt, } \\
\text { ithd, iunout, levstg, mhtli, } \\
\text { mhtlo, mhtvi, mhtvo, } \\
\text { mwfl, mwfv, newrfd = } 2 \\
\text { - istopt, ndia1 = } \\
\text { - nencl, iunlab = -1 } \\
\end{array}$ & $\begin{array}{l}\text { - Warning message } \\
\text { - }{ }^{*} \text { namlst* variable has out- } \\
\text { of-range value }\end{array}$ \\
\hline namelist.f & $\begin{array}{ll}\text { - } & \text { nhtstr, ccif, nlt }=-1 \\
\text { - } & \text { nifsh, ieos = 1 } \\
\text { - } & \text { noair, nrslv = } 2 \\
\text { - } & \text { nsend }=-2 \\
\text { - } & \text { nosets = } 3 \\
\end{array}$ & $\begin{array}{l}\text { - Warning message } \\
\text { - }{ }^{*} \text { namlst }{ }^{*} \text { variable has out- } \\
\text { of-range value }\end{array}$ \\
\hline namelist.g & $\begin{array}{ll}\text { - } & \mathrm{nsdl}, \mathrm{nspl}=-1 \\
\text { - } & \text { tpowr, timdu = -1 } \\
\text { - } & \mathrm{nsdu}, \mathrm{nspu}, \mathrm{timdl}=-2 \\
\text { - } & \mathrm{nvgrav}=2 \\
\text { - } & \text { idiag }=3\end{array}$ & $\begin{array}{l}\text { - Warning message } \\
\text { - *namlst* variable has out- } \\
\text { of-range value }\end{array}$ \\
\hline
\end{tabular}


TABLE 3

DECAY PROBLEMS

\begin{tabular}{|c|c|c|}
\hline $\begin{array}{l}\text { Problem Name } \\
\text { (base deck) }\end{array}$ & Options Tested & Results \\
\hline decay.1 & $\begin{array}{ll}\text { - } & \text { ndhx }=69 \\
\text { - } & \text { irpwty }=11 \\
\text { - } & \text { nsend }=3\end{array}$ & Exercise subroutine decay \\
\hline decay. 2 & $\begin{array}{ll}\text { - } & \text { ndhx }=71 \\
\text { - } & \text { irpwty }=11\end{array}$ & Exercise subroutine decay \\
\hline decay.3 & $\begin{array}{ll}\text { - } & \text { ipwrad }=1 \\
\text { - } & \text { nfbpwt }=4\end{array}$ & $\begin{array}{l}\text { - Exercise subroutine } \operatorname{rrod} 2 \\
\text { - Core dump }\end{array}$ \\
\hline decay.4 & - ipwrad =1 & $\begin{array}{l}\text { - Exercise subroutines rrod1, } \\
\text { rrod2, rhtstr } \\
\text { - Core dump }\end{array}$ \\
\hline decay.5 & $\begin{array}{ll}\text { - } & \text { irpwty = } 11 \\
\text { - } & \text { nhist }=1\end{array}$ & Exercise subroutine rrod2 \\
\hline decay. 6 & $\begin{array}{ll}\text { - } & \text { iprwty }=11 \\
\text { - } & \text { nhist }=1 \\
\text { - } & \text { ndhx }=-11\end{array}$ & Exercise subroutine rrod2 \\
\hline decay.7 & $\begin{array}{ll}\text { - } & \text { irpwty }=11 \\
\text { - } & \text { nhist }=2 \\
\text { - } & \text { ndhx }=-11 \\
\end{array}$ & Exercise subroutine rrod2 \\
\hline decay. 8 & $\begin{array}{ll}\text { - } & \text { irpwty }=11 \\
\text { - } & \text { nhist }=2 \\
\text { - } & \text { ndhx }=69\end{array}$ & Exercise subroutine rrod2 \\
\hline
\end{tabular}

subroutine was completely exercised. Including these problems in the expanded test matrix improved the coverage in "rrod2" and completely tested subroutine "decay".

The base deck for the decay model problems is the modified ZION-PWR plant model. The first problem, decay.1, uses the ANS-79 decay-heat standard by assigning $n d h x=69$ and irpwty $=11$. The variable ndhx is the number of decay-heat groups, and irpwty is the option for neutronic point-reactor kinetics. The second problem assigns ndhx $=71$, which defines the ANS-79 decay-heat standard plus heavyelement decay for ${ }^{239} \mathrm{U}$ and ${ }^{239} \mathrm{~Np}$. A third input deck was created to test the 2D axial power-shape table setting ipwrad $=1$, and the various options for nfbpwt were exercised. The variable nfbpwt is the option for replacing the radial, axial, and/or the horizontal plane power shapes with another user-defined shape volume averaging the reactivity feedback parameter over the core region. 
The variable nhist allows the user three options for power history. Option zero is selected when the user inputs the delayed neutron precursor concentration (cdgn) and the decay-heat precursor concentration (cdhn). Option nhist $=0$ is the selection used in all Standard Test Matrix problems. To exercise the code further, the other options for nhist are input. When nhist is assigned a value of 1 , cdgn and cdhn are calculated assuming an infinite history of operation at the user input power level of rpowri. If nhist is $\geq 2$, a power history table will be input with the number of data pairs being the value of nhist; this is then used to calculated cdgn and cdhn.

Problems decay.5, decay.6, decay.7, and decay.8 test the nhist options with a variety of other variables to exercise subroutine "rrod2".

Two problems were created from the base deck of w4loopn from the Standard Test Matrix to test the subroutine "dtdiag". The subroutine "dtdiag" is a timestep-size diagnostic used for the tromsg file. The first deck assigns the namelist variables tsdls $=1$ and tsdus $=20$. The second problem assigns tsdlt $=1.0$ and tsdut $=200.0$. These two problems improve the coverage of dtdiag from $0 \%$ to $68 \%$. Table 4 lists the problem names and the input options for the timestep diagnostic problems.

Numerous problems were created to test the heat-structure and vessel components further. Table 5 lists the problems, options, and results of the new test problems. Problems core.1, core.2, and core. 3 test the 2D power-shape option ipwrad $=1$ with various other parameters, as listed in Table 5. The variable ipwdep is the powershape table-dependence option. This option is set to -1 , which exercises the powershape table dependence defined for each node by a signal-variable or control-block identification number. The node power density and the resulting power shape are not normalized by TRAC-P/MOD2 to a spatially averaged value of unity in problems core. 2 and core.3. In problem core.1, ipwdep is set to 1 , which exercises the power-shape table dependence defined for each node by a signal-variable or controlblock identification number. The node power density and the resulting power shape are normalized by TRAC-P/MOD2 to a spatially averaged value of unity. Also, in problems core. 2 and core.3, the option nrpwr is set to 2, which defines the number of rod axial or slab thickness locations for the $2 \mathrm{D}$ axial-r or axial-x power shape. In

TABLE 4

TIMESTEP DIAGNOSTIC PROBLEMS

\begin{tabular}{|c|l|c|}
\hline Problem Name & Input Options & Results \\
\hline dtdiag.1 & $\bullet \quad$ tsdls $=1$ & Exercise subroutine dtdiag \\
& $\bullet \quad$ tsdus $=20$ & \\
\hline dtdiag.2 & $\bullet \quad$ tsdlt $=1.0$ & Exercise subroutine dtdiag \\
& $\bullet \quad$ tsdut $=200.0$ & \\
\hline
\end{tabular}


TABLE 5

CORE PROBLEMS

\begin{tabular}{|c|c|c|}
\hline Problem Name & Options Tested & Results \\
\hline core.1 & $\begin{array}{ll}\text { - } & \text { ipwrad }=1 \\
\text { - } & \text { ipwdep }=1 \\
\text { - } & \text { nrpwr }=2\end{array}$ & $\begin{array}{l}\text { Exercise subroutines irod, } \\
\text { core1, and rrod2 }\end{array}$ \\
\hline core. 2 & $\begin{array}{ll}\text { - } & \text { ipwdep }=-1 \\
\text { - } & \text { nrpwr }=2 \\
\text { - } & \text { ipwrad }=1\end{array}$ & $\begin{array}{l}\text { Exercise subroutines irod, } \\
\text { core1 }\end{array}$ \\
\hline core. 3 & 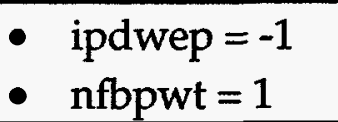 & Exercise subroutines rrod2 \\
\hline
\end{tabular}

problems core.1 and core.2, the ipwrad option, which is the spatial power shape, is assigned a value of 1 , which uses a $2 \mathrm{D}$ axial-r or axial-x power-shape table. These problems exercise subroutines "irod", "core1", and "rrod2". The problems shown in Table 5 are based on the ZIONPWR test problem, with the key differences in the decks shown in the Options Tested column.

The 13 heat-structure problems test a variety of options in the heat-structure components that had not been exercised. These options include invalid input, hot patches, multiple 1D hydraulic component coupling, adiabatic boundary conditions, and external thermocouples. The majority of these problems are based on the ZIONPWR, except where noted in Table 6 (the problem is described in Ref. 1). A listing of the heat-structure problems and the options exercised, along with the results, is shown in Table 6.

Heatstructure.1 is from the ZIONPWR problem. In this problem, the reflood option is not activated by assigning newrfd $=0$, but the hotpatch is initiated with ipatch $=1$. The goal was to confirm that the proper error was displayed. In Heatstructure.2, the reflood model was turned on in the namelist options (newrfd $=1$ ). This problem is based on cctf54 and tests the coding for the hotpatch modeling. Problem heatstructure.4 turns on the namelist option ithd, which allows the input of heattransfer diameters through variables hdri and hdro for heat-structure components. Problem heatstructure.10 turns on the heat-structure option for multiple 1D component coupling. This option was not exercised in the other test problems. Problem heatstructure.11 sets ittc $=1$, which is the specification of an external thermocouple on the ROD or SLAB element surface. In addition, the tc array card 48 of the heat-structure component is added.

Problems heatstructure.3, 5, 6, 7, 8, 9, and 12 test input error and warning message coding. These problems intentionally input improper data to check the warning messages. 
TABLE 6 HEAT-STRUCTURE PROBLEMS

\begin{tabular}{|c|c|c|}
\hline Problem Name & Options Selected & Results \\
\hline heatstructure.1 & $\begin{array}{ll}- & \text { newrfd }=0 \\
- & \text { ipatch }=1 \\
- & \text { slab }\end{array}$ & $\begin{array}{l}\text { Error messages } \\
\text { *rhtstr* newrfd.eq.1 models hot } \\
\text { patches }\end{array}$ \\
\hline $\begin{array}{l}\text { heatstructure. } 2 \\
\text { cctf54 }\end{array}$ & $\begin{array}{ll} & \text { newrfd =1 } \\
- & \text { ipatch }=1 \\
\text { - } & \text { slab } \\
\end{array}$ & Hot-patch modeling \\
\hline heatstructure. 3 & $\begin{array}{ll}\text { idbci }=0 \\
\text { idbco }=0\end{array}$ & $\begin{array}{l}\text { Warning } \\
\text { - } \quad{ }^{*} \text { rhstr* either idbco or idbci must be } \\
2\end{array}$ \\
\hline heatstructure.4 & $\begin{array}{ll}- & \text { hdri }=0 \\
- & \text { idbci }=0 \\
\text { - } & \text { idbco }=2 \\
\text { - } & \text { ithd }=1 \\
\end{array}$ & $\begin{array}{l}\text { Namelist option to input heat-transfer } \\
\text { diameters through variable HDRI }\end{array}$ \\
\hline heatstructure.5 & $\begin{array}{ll}- & \text { idbco }=0 \\
\text { - } & \text { idbci }=2 \\
\text { - } & \text { hdri }=0.000 \\
\text { - } & \text { ithd }=1 \\
\end{array}$ & $\begin{array}{l}\text { Warning } \\
\text { *thstr" hdri must be } . g t .0 \\
\text { - When ithd }=1 \text { and idbci }=2 \text {, then } \\
\text { hdri }=0.000 \text { must be }>0\end{array}$ \\
\hline heatstructure.6 & $\begin{array}{ll}- & \text { hdro }=0 \\
- & \text { idbci }=0 \\
- & \text { idbco }=2 \\
\text { - } & \text { ithd }=1\end{array}$ & $\begin{array}{l}\text { Warning } \\
\quad \text { *thstr } \\
\end{array}$ \\
\hline heatstructure.7 & nodes $=28$ & $\begin{array}{l}\text { Warning } \\
\text { - } \quad{ }_{\text {rhstr }}^{*} \text { dimension nzfmx .lt. nodes }\end{array}$ \\
\hline heatstructure. 8 & $\begin{array}{ll}\text { - } & \text { nzmax }=250 \\
\text { - } & \text { ncrz }=400\end{array}$ & $\begin{array}{ll} & \text { Warning } \\
\text { - } & \text { rhstr* dimension nzfmx .lt. ncrz+1 }\end{array}$ \\
\hline heatstructure.9 & $\begin{array}{ll}- & \mathrm{q} 235=0 \\
- & \mathrm{q} 239=0 \\
- & \mathrm{q} 238=0 \\
& \mathrm{qavg}=0 \\
- & \text { r239pf }=0 \\
- & \text { fishpi }=-.1 \\
& \text { rans }=-.1\end{array}$ & $\begin{array}{ll} & \text { *rrod1 bad input q235 } \\
\text { - } & \text { *rrod1 bad input q238 } \\
\text { - } & \text { *rod1 bad input q239 } \\
\text { - } & \text { *rrod1 bad input qavg } \\
\text { - } & \text { *rhtstr" q235 cannot be.le.zero } \\
\text { - } & \text { *rhtstr* q238 cannot be.le.zero } \\
\text { - } & \text { *rhtstr } \text { q239 cannot be.le.zero } \\
\text { - } & \text { *rhtstr* qavg cannot be.le.zero } \\
\text { - } & \text { *rhtstr r239pf cannot be.le.zero } \\
\text { - } & \text { *rhtstr* rans cannot be.le.zero } \\
\text { - } & \text { *rhtstr* fishpi cannot be.le.zero }\end{array}$ \\
\hline heatstructure.10 & $\operatorname{mld}=1$ & $\begin{array}{l}\text { Option for multiple 1D hydraulic } \\
\text { component coupling }\end{array}$ \\
\hline heatstructure.11 & $\begin{array}{ll} & \text { ittc }=1 \\
- & \text { array tc } \\
\end{array}$ & $\begin{array}{l}\text { Model thermocouple on slab or rod } \\
\text { option }\end{array}$ \\
\hline heatstructure.12 & $\begin{array}{ll}- & \text { mhtli }=1 \\
\text { - } & \text { mhtlo }=1 \\
\text { - } & \text { mhtvi }=1 \\
\text { - } & \text { mhtvo }=1 \\
\text { - } & \text { htmli }=1.4000 \\
\text { - } & \text { htmlo }=1.4000\end{array}$ & $\begin{array}{l}\text { Warning } \\
\text { - }{ }^{*} \text { rhtstr* htmli is outside range }^{*}(0.9,1.1) \\
\text { * }{ }^{*} \text { rhtstr } \text { htmlo is outside range } \\
(0.9,1.1)\end{array}$ \\
\hline heatstructure.13 & nend $=1$ & Warning \\
\hline
\end{tabular}




\section{LA-UR-98-959}

There was some concern with the control system regarding the ability of the test problems to exercise. A detailed investigation of the control system resulted in the creation of five short problems.

We examined each of the subroutines included in the control system and found that the vast majority of the unexercised coding in these subroutines is for invalid input tests and warning messages. In the control system subroutines, there were approximately 700 lines of coding for valid input data tests and the corresponding user warning messages.

To improve the coverage of subroutine "conblk", five short problems were created. These problems test a few of the invalid user input warning messages in conblk. Problem conblock.5 tests coding, which evaluates xout when xtau1 and xtau2 are complex valued roots. Table 7 lists the problem names, the input options, and the results of the problems.

A significant portion of the unexercised coding tests the input and if the input is invalid displays a warning message. Ten test problems with invalid input were created to improve the code coverage in subroutine "input" and subroutine "rvssl". Table 8 lists the problem name, the input options, and the problem results.

The namelist options mwfl and mwfv allow input of the wall-to-liquid wall-friction multiplicative design factors and the wall-to-gas wall-friction multiplicative design factors, respectively. Initiating this option requires that $\mathrm{mwfl}=1$ or $\mathrm{mwfv}=1$ in the namelist; additional array input is required by the pipe, pump, tee, valve, and vessel components. A problem was created to exercise the coding for mwfl $=1$ and $\mathrm{mwfv}=1$. The problem name, input options, and results are shown in Table 9. The problems in Table 9 are based on utube3d, which is described in Ref. 1. The modifications to the problem are shown in Table 9 in the input options column. The problems mwfl and mwfv further exercise the subroutine "rvssl".

TABLE 7

CONBLK TEST PROBLEMS

\begin{tabular}{|c|l|l|}
\hline Problem Name & \multicolumn{1}{|c|}{ Input Options } & \multicolumn{1}{|c|}{ Results } \\
\hline conblock.1 & icbn $=71$ & $\begin{array}{l}\text { *conblk } \\
\text { operation number }\end{array}$ \\
\hline conblock.2 & cbcon2 $=-4.000$ & $\begin{array}{l}\text { *onblk* invalid dead } \\
\text { function constants }\end{array}$ \\
\hline conblock.3 & cbcon1 $=1.000 \mathrm{e}-20$ & Exercise conblk subroutine \\
\hline conblock.4 & cbgain $=0.000$ & Exercise conblk subroutine \\
\hline conblock.5 & $\begin{array}{l}\text { - cbcon1 }=1.000 \mathrm{e}-10 \\
\text { cbcon2 }=5.500 \mathrm{e}-21\end{array}$ & Exerise conblk subroutine \\
\hline
\end{tabular}


TABLE 8

INPUT ERROR PROBLEMS

\begin{tabular}{|c|c|c|}
\hline Problem Name & Input Options & Results \\
\hline input.1 & no namelist data & $\begin{array}{l}\text { *input* inopts namelist data } \\
\text { not found }\end{array}$ \\
\hline input. 2 & nccfl $=15$ & ${ }^{*}$ input* nccfl is out of bounds \\
\hline input.3 & matb $=45$ & $\begin{array}{l}\text { *input* illegal material ID } \\
\text { number }\end{array}$ \\
\hline input.4 & $\mathrm{tp}=-0.0762$ & $\begin{array}{l}{ }^{*} \text { load* not enough data to fill } \\
\text { array }\end{array}$ \\
\hline input.5 & isolut $=0$ & ${ }^{*}$ input* ${ }^{*}$ isolut $=0$ instead of 1 \\
\hline vessel.1 & ivssbf $=1$ & ${ }^{*}$ rvssl ${ }^{*}$ illegal value for ivssbf \\
\hline vessel.2 & $\begin{array}{ll}\text { - } & \text { iconc }=1 \\
\text { - } & \text { isolut }=0\end{array}$ & $\begin{array}{l}\text { *rcomp* iconc and isolut are } \\
\text { inconsistent }\end{array}$ \\
\hline vessel.3 & nsgrid $=-1$ & ${ }^{*}$ rvssl $^{*}$ nsgrid must .ge.0 \\
\hline vessel.4 & $\begin{array}{ll}\text { - } & \text { nsgrid }=1 \\
\text { - } & \text { newrfd }=0\end{array}$ & $\begin{array}{l}\text { * } \text { rvssl }^{*} \text { newrfd }=1 \text { to model } \\
\text { spacer grids }\end{array}$ \\
\hline vessel.5 & iext $=1$ & Core dump \\
\hline
\end{tabular}

TABLE 9

MWFL AND MWFV PROBLEMS

\begin{tabular}{|c|c|c|}
\hline Problem Name & Input Options & Results \\
\hline mwfl & $\begin{array}{ll}\text { - } & \text { mwfl }=1 \\
\text { - } & \text { array wfmfl }\end{array}$ & Exercise subroutine rvssl \\
\hline $\mathrm{mwfv}$ & $\begin{array}{l}\text { - } \quad \operatorname{mwfv}=1 \\
\text { - } \quad \text { array wfmfv }\end{array}$ & Exercise subroutine rvssl \\
\hline
\end{tabular}

In subroutine "rvssl", there were various areas of coding that were not exercised. Problems to exercise rvssl further are shown in Table 10. Problem cfz3g is based on the utube3d problem, and rvssl is based on the msr2 problem described in Ref. 1.

Problem rvssl.2 is based on utube3d, which is described in Ref. 1. There is an option in the namelist variables to input the data for certain parameters only once in the namelist. Default values can be assigned to alp, cfz3, hd3, hstn, p, pa, qppp, vl, vv, tv, and $t l$ when istopt is 1 or 2 . Istopt is set to 2 so that the input data cards for the arrays above remain but are overridden by the namelist values.

Problems napcss, napcss.1, and napcss. 2 are based on the loftk input deck described in Ref. 1. The parameter napcss is the controller type used in the CSS controller card. Various controller types are not exercised in the Standard Test Matrix. To exercise 
TABLE 10

RVSSL PROBLEMS

\begin{tabular}{|c|c|c|}
\hline Problem Name & Input Options & Results \\
\hline $\mathrm{cfz3g}$ & $\begin{array}{l}\text { - } \quad \text { istopt }=2 \\
\text { - } \quad \mathrm{cfz} 3=2.2 \\
\text { - } \quad \mathrm{nfrc3}=2\end{array}$ & Exercise subroutine rvssl \\
\hline rvssl & $\begin{array}{ll}\text { - } & \text { gytc }=3.0 \\
\text { - } & \text { gxrc }=4.0 \\
\text { - } & \text { igeom }=0 \\
\text { - } & \text { ntsx }=3\end{array}$ & $\begin{array}{l}\text { Exercise subroutine rvssl } \\
\text { *Fatal Error* }\end{array}$ \\
\hline rvss1.2 & $\begin{array}{l}\text { - istopt }=2 \\
\text { - hd3, alp, vv, vl, } \\
\text { tv, tl, p, pa input } \\
\text { in namelist }\end{array}$ & Exercise subroutine rvssl \\
\hline rvssl.3 & nvent $=1$ & Exercise subroutine rvssl \\
\hline napcss & napcss $=7,8,10,12$ & Exercise subroutine rvssl \\
\hline napcss.1 & napcss $=9,14$ & Exercise subroutine rvssl \\
\hline napcss. 2 & napcss $=6,13,14$ & Exercise subroutine rvssl \\
\hline
\end{tabular}

the coding in subroutine "rvssl", the values of the variable napcss are modified, as shown in Table 10.

The subroutines "femom", femomx", "femomy", and "femomz" contained a large portion of unexercised coding. An investigation to exercise this coding resulted in the creation of one problem and the discovery of numerous lines of dead coding, which are described in the Code Issues section of this document. Table 11 lists the femom problems, input options, and results. The problem in Table 11 is based on the msr2 problem, which is described in Ref. 1.

There is an option in the pipe and tee components for allowing power to the fluid and an option in the pump to allow wall heat transfer. In the Standard Test Matrix,

TABLE 11

FEMOM PROBLEM

\begin{tabular}{|l|l|c|}
\hline Problem Name & Input Options & Results \\
\hline femom & $\begin{array}{l}\bullet \text { ivssbf }=2 \\
\bullet\end{array}$ & igeom $=0$
\end{tabular}




\section{LA-UR-98-959}

these options are not adequately tested. The power-to-the-wall option in the pump component was not sufficiently exercised. The table input for these options is a key feature that must be exercised for the pipe, pump, and tee components. Initiating this option then requires the user to input various cards and arrays for the components, which further exercises the subroutines.

Four problems were created to exercise the subroutines "rtee", "rpipe", and "rpump". The problem name, options tested, and results are listed in Table 12; these problems are based on the inrenode.61 problem described in Section 2.9 of this document. These problems improve the coverage of the pipe, pump, and tee components and test the qppp component options.

TABLE 12

\section{QPPP PROBLEMS}

\begin{tabular}{|c|c|c|}
\hline Problem Name & Input Options & Results \\
\hline Tee.1 & $\begin{array}{ll} & \text { ipow1 } 1=1 \\
\text { - } & \text { npwtb1 }=2 \\
\text { - } & \text { npwrfl }=2 \\
\text { - } & \text { nqptb1 }=2 \\
\text { - } & \text { nqprfl }=2 \\
\text { - } & \text { qpin1 } 1=1.0 \\
\text { - } & \text { additional arrays } \\
& \text { powrf1, qp3tb1, and } \\
& \text { qp3rf1 }\end{array}$ & $\begin{array}{l}\text { Exercise qppp option on } \\
\text { primary side in subroutine } \\
\text { rtee }\end{array}$ \\
\hline Tee. 2 & $\begin{array}{ll} & \text { ipow2 } 21 \\
\text { - } & \text { npwtb2 }=2 \\
\text { - } & \text { npwrf2 }=2 \\
\text { - } & \text { nqptb2 }=2 \\
\text { - } & \text { nqprf2 }=2 \\
\text { - } & \text { qpin2 }=1.0 \\
\text { - } & \text { additional arrays } \\
& \text { powrf2, qp3tb2, and } \\
& \text { qp3rf2 }\end{array}$ & $\begin{array}{l}\text { Exercise qppp options on } \\
\text { secondary side in } \\
\text { subroutine rtee }\end{array}$ \\
\hline Pipe & $\begin{array}{ll}- & \text { ipow }=1 \\
- & \text { npowtb }=2 \\
- & \text { npowrf }=2 \\
\text { - } & \text { arrays qp3tb and } \\
& \text { qp3rf }\end{array}$ & Exercise subroutine rpipe \\
\hline Pump & $\begin{array}{ll}\text { - } & \text { nqp3rf }=2 \\
\text { - } & \text { array qf3rt }\end{array}$ & Exercise subroutine rpump \\
\hline
\end{tabular}




\section{LA-UR-98-959}

\section{CODE ISSUES}

During this investigation, code bugs and areas of dead coding were discovered. To expand the coverage of the code, subroutines that contained large sections of untouched coding were identified; problems then were created to meet the conditions that should exercise the coding. In a few instances, the response of the code to input decks was not as expected, which led to the discovery of code bugs.

One of these cases was unexercised coding for a three-dimensional (3D) vessel undergoing reflood. In two subroutines, "htif" and "cif3", a conditional of these options had to be met to exercise large sections of coding. Various input decks were added to the expanded test set to exercise these coding sections, such as FLECHTSEASET and cctf54. However, the problems were unsuccessful in exercising these sections of coding. It was determined that both of these subroutines contained a code bug that has been resolved in Ver. 5.4.29+ of TRAC-P/MOD2. This code bug was brought to the attention of the TRAC-M/f90 development team, and flags were placed in the code to ensure that the bug would be fixed later.

Areas of dead and developer coding exist in TRAC-P/MOD2, Ver. 5.4.25, which were identified during this investigation. Dead coding is code that cannot be exercised through input deck options. In some situations, the dead coding can be considered developer coding. The developer coding was added to TRAC-P/MOD2, Ver. 5.4.25 for the use of the code developers, but it is not an option for the users to initiate. This coding may be considered dead coding or developer coding; however, it is not coding that can be exercised without modifying the source code. Two areas of dead coding were found. One section was discovered in "femom" and another in the subroutines "sgeev", "hqr2t", "ortrant", and "balbakt". In addition to these two areas, many subroutines are platform dependent and are not called anywhere in TRAC-P/MOD2.

Over 100 lines of dead coding were found in the subroutine "femom". This coding is initiated with a test on a variable iepri. The variable iepri is fixed in the Ver. 5.4.25 coding. The only way to test this section of coding would be to modify the Ver. 5.4.25 source code. This item also has been brought to the attention of the TRAC-M/f90 development team, and flags were placed in the code to ensure that the dead coding will be fixed later.

In the subroutine "sgeev", there is a variable named job that must not be equal to zero to initiate calls to "hqr2t", "balbakt", "scopyt", "scopym", and "ortrant". The variable job is defined in the call to "sgeev" as zero, and therefore, these subroutines will not be called. The variable job is also used in "dgbsl" as a condition for calling "ddot". These unexercised subroutines account for 450 lines of coding.

Other sections of dead coding were found in subroutines "femomx", "femomy", "femomz", and "stbme3". In each of these subroutines, there are conditionals for igbcyt, igbcxr, and igbcz. The variables igbcxr and igbcyt always will be equal to zero, whereas igbcz can be equal to zero or one. In subroutines "femomx", "femomy", 


\section{LA-UR-98-959}

"femomz", and "stbme3", there are 175 lines that can never be exercised because it is not possible for igbcyt or igbcxr to be any value but zero.

There are many platform-dependent subroutines that are seen by the PureCoverage software and compiled but are not called for certain platforms. These subroutines include "sgbfat", "sgbslt", and "clrint", which are replaced by the subroutines "dgbfa", "dgbsl", and "ipack", respectively, depending on the platform. The subroutines "sgbfat", "sgbslt", "isamaxt", and "clrint" are called for specific platforms but should not be counted in the coverage statistics. These four subroutines account for 145 lines of executable coding.

Many subroutines are included in the source coding but have no calls from any other subroutine in the code. The list of routines that have no calls in the code and a description of the routine are shown below:

- vdpcss defines the two signal variables for inlet and outlet pressure and defines the two control blocks for the subtract and pi controller needed to adjust flow resistance through the vessel.

- ring0 initializes variables for the inner-ring radial boundary to allow more general loops.

- unpkit unpacks data packed by packit.

- rsperr is a support routine for IBM.

- switch moves one level of vessel data starting at IADD1 to IADD2 and vice versa.

- movlev is called by the switch to copy $n$ elements from array A to array B.

- setic is a routine that is not currently used.

- modify is the control program for the interactive modification capability.

These routines are not called and account for another 100 lines of executable coding.

Overall, the dead coding and code bugs account for a significant portion of unexercised coding. The items listed above account for $2.8 \%$ of TRAC-P/MOD2, Ver. 5.4.25.

\section{UNSUPPORTED CODE}

The archival version of TRAC-P/MOD2 contains models and components that are no longer supported. These components include the turbine, containment, and steam separator. A listing of the subroutines for unsupported coding is shown in Table 13, along with the number of lines of unexercised executable coding. The 
TABLE 13

UNSUPPORTED TRAC-P/MOD2 CODING

\begin{tabular}{|c|c|}
\hline Subroutine & $\begin{array}{c}\text { Number of Unused } \\
\text { Executable Code Lines }\end{array}$ \\
\hline ssepor & 303 \\
\hline rturb & 189 \\
\hline sepdi & 137 \\
\hline sgecot & 96 \\
\hline returb & 86 \\
\hline trpow & 86 \\
\hline turb1 & 83 \\
\hline returb & 86 \\
\hline sgbfat & 60 \\
\hline iturb & 57 \\
\hline sgbslt & 51 \\
\hline wturb & 46 \\
\hline sepdx & 35 \\
\hline igturb & 34 \\
\hline turb3 & 22 \\
\hline loctrb & 13 \\
\hline turb2 & 12 \\
\hline dturb & 10 \\
\hline trbpre & 68 \\
\hline trbpst & 23 \\
\hline ctain1 & 3 \\
\hline ctain2 & 3 \\
\hline ctain3 & 3 \\
\hline & \\
\hline & \\
\hline
\end{tabular}

subroutines in Table 13 account for $2.7 \%$ of the TRAC-P/MOD2, Ver. 5.4 .25 executable coding.

Numerous subroutines contain conditional tests for types equal to either sepdh, ctainh, or turbh. The coding following these conditionals is not tested. The subroutines that contain unsupported coding include the following subroutines: tee1, tee2, tee3, rtee, icomp, ihpss1, dmpit, xtvdr, out1d, prep1d, post, rdcomp, rdrest, srt1p, tf1ds1, and tf1ds.

There are certainly numerous other subroutines that contain further unsupported coding and that have yet to be identified. Overall, the executable coding for the separator, containment, and turbine make up $>3 \%$ of TRAC-P/MOD2,Ver. 5.4.25. 


\section{REMAINING CODE CHARACTERISTICS}

In almost every subroutine containing unexercised coding, there are numerous warning messages. These messages account for approximately five lines of coding each. The number of unexercised messages is especially heavy in subroutines "rtee", "rpump", "rvlv", "rhstr", "rvssl", "rpipe", and "rfill". Each of these subroutines reads input data for specific TRAC-P/MOD2 components. Some warning messages are similar for each of these subroutines. Figure 1 is an example of the unexercised error message coding that is seen; this message is repeated in each of the previously mentioned subroutines. Figure 1 is extracted from subroutine "rvlve" from the PureCoverage file. The numbers in the left-hand column are the number of times the line has been executed; in this section of coding, the error message has not been hit, as indicated by the zeros in the left-hand column beside the coding.

In Appendix A, there is a listing of the PureCoverage results after running the Expanded Standard Test Matrix. In the PureCoverage file, the total number of executable lines of coding in each subroutine is shown, and the number of lines that

$$
\begin{aligned}
& 5901 \text { if(lenvlt.le.lendim) go to } 5 \\
& 01 \text { newlim=lenvlt+3 } \\
& 01 \text { write(imout,3) lendim,lenvlt,newlim,newlim } \\
& \text { 01 write( iout,3) lendim,lenvlt,newlim,newlim } \\
& \text { 01 write( } \text { itty,3) lendim,lenvlt,newlim,newlim } \\
& \text { I } 3 \text { format }\left(/{ }^{\prime} \text { current value of lendim }=', 16 \text {,' and lenvlt }=\right.\text { ',i6/ } \\
& \text { I } 1 \text { ' increase lendim to',16,' in blkdat and dimension', } \\
& \text { I } 2 \text { ' vlt to',i6,' in genvlt') } \\
& 0 \text { I jflag }=1 \\
& 01 \text { call error(2,'*rvlve* vlt size exceeds its limit',4) } \\
& 590 \text { I } 5 \text { continue }
\end{aligned}
$$

Fig. 1. Example of an error message seen throughout the TRAC-P/MOD2, Ver. 5.4.25 source coding. This coding is from subroutine "rvlve" and is in the format produced by PureCoverage. 
are exercised, along with the percentage of the subroutine exercised, is listed. From a cursory examination of the results, it might be thought that significant gains could be made in some of the subroutines. At this point, we have concluded that the cost of increasing the code coverage is high relative to the improvements to the code coverage.

We have determined that a significant portion of the remaining untested coding is warning or error messages. To give an example of the number of code lines that are error or warning messages for invalid or inconsistent user input data, a few of the subroutines that contained a significant number of unused lines of coding were examined and the error and warning message code lines were tallied. In the following routines, there are a total of 531 lines of unexercised warning or error message coding: rvlve, choke, rtee, rrod2, ihpss3, rhstr, core1, rvssl, rcntl, and ihpss1. This is a significant portion of the subroutines' unexercised coding.

Numerous options were added to the expanded test problems to exercise areas of the code that were not exercised by the Standard Test Matrix. Numerous code bugs, dead or developer coding, and unsupported coding were discovered during this investigation. There is, with only a few exceptions, a limited number of problems that can be developed to exercise the physics and the models of TRAC-P/MOD2 further. The cost to create these problems is high relative to the additional coverage to TRAC-P/MOD2. The majority of the unexercised coding remaining in TRAC$\mathrm{P} / \mathrm{MOD} 2$ is in response to invalid or inconsistent user-input data. After careful examination of the code, we recommend that this activity be concluded.

\section{REFERENCES}

1. Robert G. Steinke, "A Description of the Test Problems in the TRAC-P Standard Test Matrix," Los Alamos National Laboratory report LA-UR-96-1475 (May 1996).

2. Pure Atria, PureCoverage: Users Guide (Pure Atria, Sunnyvale, California, 1996).

3. Kin L. Lam, "Implementation of a Radiation Heat Transfer Model into the TRAC Code," Los Alamos National Laboratory report LA-UR-96-0174 (October 1995).

4. B. E. Boyack and E. D. Hughes, "TRAC-P Validation Test Matrix," Los Alamos National Laboratory report LA-UR-97-3990 (September 1997).

5. J-C. Lin, V. Martinez, and J. W. Spore, "TRAC-PF1/MOD2 Developmental Assessment Manual," Los Alamos National Laboratory draft report (August 1993).

6. H. Akimoto, Y. Kozawa, A. Inoue, and S. Akoi, "Analysis of Direct Contact Condensation of Flowing Steam onto Injected Water with Multifluid Model of Two-Phase Flow," Journal of Nuclear Science and Technology 20:12, pp. 10061022 (December 1983). 
LA-UR-98-959

7. L. A. Guffee, S. B. Woodruff, R. G. Steinke, and J. W. Spore, "TRAC-PF1/MOD2 Code Manual Programmers Guide," US Nuclear Regulatory Commission report NUREG/CR-5673 (July 1992).

8. J. W. Spore, S. Jolly-Woodruff, T. Knight, J-C. Lin, R. Nelson, K. Pasamehmetoglu, R. Steinke, and C. Unal, "TRAC-PF1/MOD2: Volume 1: Theory Manual," US Nuclear Regulatory Commission report NUREG/CR-5673 (1993). 


\section{LA-UR-98-959}

\section{APPENDIX A}

Adjusted unused unused used lines

used \%

unused

used

used \%

\begin{tabular}{|c|c|c|c|c|c|c|}
\hline$=========$ & $=======$ & $========$ & $==== \pm===$ & $========$ & $========$ & $========$ \\
\hline Total Coverage & 52 & 534 & $91 \%$ & 9094 & 45857 & $83 \%$ \\
\hline ssepor.f & 1 & 0 & $0 \%$ & 303 & 0 & $0 \%$ \\
\hline hqr2t.f & 1 & 0 & $0 \%$ & 263 & 0 & $0 \%$ \\
\hline htif.f & 0 & 1 & $100 \%$ & 256 & 467 & $64 \%$ \\
\hline cif3.f & 0 & 1 & $100 \%$ & 250 & 587 & $70 \%$ \\
\hline recntl.f & 0 & 1 & $100 \%$ & 219 & 476 & $68 \%$ \\
\hline rturb.f & 1 & 0 & $0 \%$ & 189 & 0 & $0 \%$ \\
\hline choke.f & 0 & 1 & $100 \%$ & 176 & 383 & $68 \%$ \\
\hline rtee.f & 0 & 1 & $100 \%$ & 172 & 206 & $54 \%$ \\
\hline rvlve.f & 0 & 1 & $100 \%$ & 171 & 160 & $48 \%$ \\
\hline femom.f & 0 & 1 & $100 \%$ & 159 & 1066 & $87 \%$ \\
\hline ihpss3.f & 0 & 1 & $100 \%$ & 149 & 510 & $77 \%$ \\
\hline rhtstr.f & 0 & 1 & $100 \%$ & 149 & 762 & $83 \%$ \\
\hline ihpss1.f & 0 & 1 & $100 \%$ & 143 & 785 & $84 \%$ \\
\hline sepdi.f & 1 & 0 & $0 \%$ & 137 & 0 & $0 \%$ \\
\hline sfa55v.f & 1 & 0 & $0 \%$ & 136 & 0 & $0 \%$ \\
\hline core1.f & 0 & 1 & $100 \%$ & 132 & 898 & $87 \%$ \\
\hline femomy.f & 0 & 1 & $100 \%$ & 114 & 321 & $73 \%$ \\
\hline rentl.f & 0 & 1 & $100 \%$ & 110 & 721 & $86 \%$ \\
\hline ivssl.f & 0 & 1 & $100 \%$ & 108 & 362 & $77 \%$ \\
\hline dtdiag.f & 0 & 1 & $100 \%$ & 107 & 228 & $68 \%$ \\
\hline trpset.f & 0 & 1 & $100 \%$ & 101 & 474 & $82 \%$ \\
\hline rvssl.f & 0 & 1 & $100 \%$ & 100 & 713 & $87 \%$ \\
\hline
\end{tabular}


LA-UR-98-959

\begin{tabular}{|c|c|c|c|c|c|c|}
\hline load.f & 0 & 1 & $100 \%$ & 96 & 216 & $69 \%$ \\
\hline sgecot.f & 1 & 0 & $0 \%$ & 96 & 0 & $0 \%$ \\
\hline namlst.f & 0 & 1 & $100 \%$ & 94 & 590 & $86 \%$ \\
\hline aivssl.f & 0 & 1 & $100 \%$ & 91 & 61 & $40 \%$ \\
\hline conblk.f & 0 & 1 & $100 \%$ & 89 & 413 & $82 \%$ \\
\hline htvssl.f & 0 & 1 & $100 \%$ & 87 & 602 & $87 \%$ \\
\hline zcore.f & 0 & 1 & $100 \%$ & 87 & 297 & $77 \%$ \\
\hline returb.f & 1 & 0 & $0 \%$ & 86 & 0 & $0 \%$ \\
\hline trbpow.f & 1 & 0 & $0 \%$ & 86 & 0 & $0 \%$ \\
\hline thermd.f & 0 & 1 & $100 \%$ & 85 & 143 & $62 \%$ \\
\hline turb1.f & 1 & 0 & $0 \%$ & 83 & 0 & $0 \%$ \\
\hline rpump.f & 0 & 1 & $100 \%$ & 80 & 208 & $72 \%$ \\
\hline tf3ds3.f & 0 & 1 & $100 \%$ & 70 & 546 & $88 \%$ \\
\hline icomp.f & 0 & 1 & $100 \%$ & 69 & 252 & $78 \%$ \\
\hline trbpre.f & 0 & 1 & $100 \%$ & 68 & 7 & $9 \%$ \\
\hline tf3ds1.f & 0 & 1 & $100 \%$ & 65 & 514 & $88 \%$ \\
\hline offtke.f & 0 & 1 & $100 \%$ & 64 & 54 & $45 \%$ \\
\hline rbreak.f & 0 & 1 & $100 \%$ & 64 & 133 & $67 \%$ \\
\hline $\operatorname{rrod} 2 . f$ & 0 & 1 & $100 \%$ & 63 & 448 & $87 \%$ \\
\hline tfplbk.f & 0 & 1 & $100 \%$ & 63 & 164 & $72 \%$ \\
\hline fillx.f & 0 & 1 & $100 \%$ & 62 & 178 & $74 \%$ \\
\hline femomx.f & 0 & 1 & $100 \%$ & 61 & 372 & $85 \%$ \\
\hline sgbfat.f & 1 & 0 & $0 \%$ & 60 & 0 & $0 \%$ \\
\hline iturb.f & 1 & 0 & $0 \%$ & 57 & 0 & $0 \%$ \\
\hline prefwd.f & 0 & 1 & $100 \%$ & 56 & 186 & $76 \%$ \\
\hline tf1ds1.f & 0 & 1 & $100 \%$ & 55 & 567 & $91 \%$ \\
\hline input.f & 0 & 1 & $100 \%$ & 51 & 902 & $94 \%$ \\
\hline
\end{tabular}


LA-UR-98-959

\begin{tabular}{|c|c|c|c|c|c|c|}
\hline sgbsit.f & 1 & 0 & $0 \%$ & 51 & 0 & $0 \%$ \\
\hline srtlp.f & 0 & 1 & $100 \%$ & 51 & 182 & $78 \%$ \\
\hline svset.f & 0 & 1 & $100 \%$ & 51 & 114 & $69 \%$ \\
\hline breakx.f & 0 & 1 & $100 \%$ & 50 & 61 & $54 \%$ \\
\hline rdrest.f & 0 & 1 & $100 \%$ & 49 & 375 & $88 \%$ \\
\hline rpipe.f & 0 & 1 & $100 \%$ & 49 & 80 & $62 \%$ \\
\hline pumpsr.f & 0 & 1 & $100 \%$ & 48 & 107 & $69 \%$ \\
\hline rcomp.f & 0 & 1 & $100 \%$ & 48 & 270 & $84 \%$ \\
\hline femomz.f & 0 & 1 & $100 \%$ & 46 & 452 & $90 \%$ \\
\hline vdpcss.f & 1 & 0 & $0 \%$ & 46 & 0 & $0 \%$ \\
\hline wturb.f & 1 & 0 & $0 \%$ & 46 & 0 & $0 \%$ \\
\hline retee.f & 0 & 1 & $100 \%$ & 44 & 110 & $71 \%$ \\
\hline sfa33v.f & 1 & 0 & $0 \%$ & 43 & 0 & $0 \%$ \\
\hline vlvex.f & 0 & 1 & $100 \%$ & 42 & 90 & $68 \%$ \\
\hline sound.f & 0 & 1 & $100 \%$ & 41 & 478 & $92 \%$ \\
\hline tf1ds.f & 0 & 1 & $100 \%$ & 41 & 853 & $95 \%$ \\
\hline fbrcss.f & 0 & 1 & $100 \%$ & 40 & 147 & $78 \%$ \\
\hline refill.f & 0 & 1 & $100 \%$ & 40 & 96 & $70 \%$ \\
\hline cbset.f & 0 & 1 & $100 \%$ & 38 & 141 & $78 \%$ \\
\hline sgeev.f & 0 & 1 & $100 \%$ & 38 & 18 & $32 \%$ \\
\hline velbc.f & 0 & 1 & $100 \%$ & 38 & 16 & $29 \%$ \\
\hline cfiles.c & 3 & 11 & $78 \%$ & 37 & 36 & $49 \%$ \\
\hline scopym.f & 1 & 0 & $0 \%$ & 37 & 0 & $0 \%$ \\
\hline ss155v.f & 1 & 0 & $0 \%$ & 37 & 0 & $0 \%$ \\
\hline ecomp.f & 0 & 1 & $100 \%$ & 36 & 195 & $84 \%$ \\
\hline aiplen.f & 0 & 1 & $100 \%$ & 35 & 26 & $42 \%$ \\
\hline sepdx.f & 1 & 0 & $0 \%$ & 35 & 0 & $0 \%$ \\
\hline
\end{tabular}


LA-UR-98-959

\begin{tabular}{|c|c|c|c|c|c|c|}
\hline htcor.f & 0 & 1 & $100 \%$ & 34 & 609 & $94 \%$ \\
\hline igturb.f & 1 & 0 & $0 \%$ & 34 & 0 & $0 \%$ \\
\hline saxpyt.f & 1 & 0 & $0 \%$ & 34 & 0 & $0 \%$ \\
\hline svset3.f & 0 & 1 & $100 \%$ & 34 & 387 & $91 \%$ \\
\hline rebrk.f & 0 & 1 & $100 \%$ & 33 & 94 & $74 \%$ \\
\hline break1.f & 0 & 1 & $100 \%$ & 32 & 69 & $68 \%$ \\
\hline prep1d.f & 0 & 1 & $100 \%$ & 32 & 134 & $80 \%$ \\
\hline rerod1.f & 0 & 1 & $100 \%$ & 32 & 262 & $89 \%$ \\
\hline rfill.f & 0 & 1 & $100 \%$ & 32 & 215 & $87 \%$ \\
\hline sdott.f & 1 & 0 & $0 \%$ & 32 & 0 & $0 \%$ \\
\hline sgefst.f & 1 & 0 & $0 \%$ & 31 & 0 & $0 \%$ \\
\hline tee1.f & 0 & 1 & $100 \%$ & 30 & 61 & $67 \%$ \\
\hline svset1.f & 0 & 1 & $100 \%$ & 29 & 337 & $92 \%$ \\
\hline ddot.f & 1 & 0 & $0 \%$ & 28 & 0 & $0 \%$ \\
\hline svseth.f & 0 & 1 & $100 \%$ & 28 & 292 & $91 \%$ \\
\hline evltab.f & 0 & 1 & $100 \%$ & 26 & 54 & $67 \%$ \\
\hline edit.f & 0 & 1 & $100 \%$ & 25 & 90 & $78 \%$ \\
\hline hout.f & 0 & 1 & $100 \%$ & 25 & 144 & $85 \%$ \\
\hline irodl.f & 0 & 1 & $100 \%$ & 25 & 104 & $80 \%$ \\
\hline isamaxt.f & 1 & 0 & $0 \%$ & 25 & 0 & $0 \%$ \\
\hline stbme3.f & 0 & 1 & $100 \%$ & 25 & 259 & $91 \%$ \\
\hline viscvd.f & 0 & 1 & $100 \%$ & 25 & 14 & $35 \%$ \\
\hline ortrant.f & 1 & 0 & $0 \%$ & 24 & 0 & $0 \%$ \\
\hline revssl.f & 0 & 1 & $100 \%$ & 24 & 361 & $93 \%$ \\
\hline volfa.f & 0 & 1 & $100 \%$ & 24 & 71 & $74 \%$ \\
\hline aicomp.f & 0 & 1 & $100 \%$ & 23 & 91 & $79 \%$ \\
\hline bkspln.f & 0 & 1 & $100 \%$ & 23 & 119 & $83 \%$ \\
\hline
\end{tabular}




\section{LA-UR-98-959}

\begin{tabular}{|c|c|c|c|c|c|c|}
\hline sscalt.f & 1 & 0 & $0 \%$ & 23 & 0 & $0 \%$ \\
\hline trbpst.f & 0 & 1 & $100 \%$ & 23 & 7 & $23 \%$ \\
\hline sasumt.f & 1 & 0 & $0 \%$ & 22 & 0 & $0 \%$ \\
\hline turb3.f & 1 & 0 & $0 \%$ & 22 & 0 & $0 \%$ \\
\hline vssssr.f & 0 & 1 & $100 \%$ & 22 & 95 & $81 \%$ \\
\hline balbakt.f & 1 & 0 & $0 \%$ & 21 & 0 & $0 \%$ \\
\hline dgbsl.f & 0 & 1 & $100 \%$ & 21 & 30 & $58 \%$ \\
\hline ring0.f & 1 & 0 & $0 \%$ & 21 & 0 & $0 \%$ \\
\hline sgeslt.f & 0 & 1 & $100 \%$ & 21 & 28 & $57 \%$ \\
\hline revlve.f & 0 & 1 & $100 \%$ & 20 & 60 & $75 \%$ \\
\hline unsvcb.f & 0 & 1 & $100 \%$ & 20 & 50 & $71 \%$ \\
\hline trans.f & 0 & 1 & $100 \%$ & 19 & 110 & $85 \%$ \\
\hline irod.f & 0 & 1 & $100 \%$ & 18 & 260 & $93 \%$ \\
\hline post3d.f & 0 & 1 & $100 \%$ & 18 & 121 & $87 \%$ \\
\hline repipe.f & 0 & 1 & $100 \%$ & 18 & 62 & $77 \%$ \\
\hline timchk.f & 0 & 1 & $100 \%$ & 18 & 30 & $62 \%$ \\
\hline unpkit.f & 1 & 0 & $0 \%$ & 18 & 0 & $0 \%$ \\
\hline chf.f & 0 & 1 & $100 \%$ & 17 & 79 & $82 \%$ \\
\hline getcrv.f & 0 & 1 & $100 \%$ & 17 & 27 & $61 \%$ \\
\hline itee.f & 0 & 1 & $100 \%$ & 17 & 150 & $89 \%$ \\
\hline readi.f & 0 & 1 & $100 \%$ & 17 & 133 & $88 \%$ \\
\hline readr.f & 0 & 1 & $100 \%$ & 17 & 377 & $95 \%$ \\
\hline rkin.f & 0 & 1 & $100 \%$ & 17 & 198 & $92 \%$ \\
\hline scopyt.f & 0 & 1 & $100 \%$ & 17 & 20 & $54 \%$ \\
\hline ssl33v.f & 1 & 0 & $0 \%$ & 17 & 0 & $0 \%$ \\
\hline evfxxx.f & 0 & 1 & $100 \%$ & 16 & 45 & $73 \%$ \\
\hline radmap.f & 0 & 1 & $100 \%$ & 16 & 42 & $72 \%$ \\
\hline
\end{tabular}




\begin{tabular}{|c|c|c|c|c|c|c|}
\hline renc1.f & 0 & 1 & $100 \%$ & 16 & 66 & $80 \%$ \\
\hline tmsfb.f & 0 & 1 & $100 \%$ & 16 & 11 & $40 \%$ \\
\hline wbreak.f & 0 & 1 & $100 \%$ & 16 & 21 & $56 \%$ \\
\hline linint.f & 0 & 1 & $100 \%$ & 15 & 36 & $70 \%$ \\
\hline zpwrci.f & 0 & 1 & $100 \%$ & 15 & 133 & $89 \%$ \\
\hline bksstb.f & 0 & 1 & $100 \%$ & 14 & 212 & $93 \%$ \\
\hline loctrb.f & 1 & 0 & $0 \%$ & 13 & 0 & $0 \%$ \\
\hline mwrx.f & 0 & 1 & $100 \%$ & 13 & 20 & $60 \%$ \\
\hline rrod1.f & 0 & 1 & $100 \%$ & 13 & 137 & $91 \%$ \\
\hline elgr.f & 0 & 1 & $100 \%$ & 12 & 101 & $89 \%$ \\
\hline igraf.f & 0 & 1 & $100 \%$ & 12 & 227 & $94 \%$ \\
\hline post.f & 0 & 1 & $100 \%$ & 12 & 212 & $94 \%$ \\
\hline rholid.f & 0 & 1 & $100 \%$ & 12 & 16 & $57 \%$ \\
\hline rholih.f & 0 & 1 & $100 \%$ & 12 & 13 & $52 \%$ \\
\hline rplen.f & 0 & 1 & $100 \%$ & 12 & 96 & $88 \%$ \\
\hline thermh.f & 0 & 1 & $100 \%$ & 12 & 235 & $95 \%$ \\
\hline trac.f & 0 & 1 & $100 \%$ & 12 & 111 & $90 \%$ \\
\hline turb2.f & 1 & 0 & $0 \%$ & 12 & 0 & $0 \%$ \\
\hline bfgrf.f & 0 & 1 & $100 \%$ & 11 & 53 & $82 \%$ \\
\hline ivlve.f & 0 & 1 & $100 \%$ & 11 & 57 & $83 \%$ \\
\hline rdcomp.f & 0 & 1 & $100 \%$ & 11 & 48 & $81 \%$ \\
\hline rsperr.f & 1 & 0 & $0 \%$ & 11 & 0 & $0 \%$ \\
\hline seteod.f & 0 & 1 & $100 \%$ & 11 & 42 & $79 \%$ \\
\hline seteoh.f & 0 & 1 & $100 \%$ & 11 & 53 & $82 \%$ \\
\hline wir.f & 0 & 1 & $100 \%$ & 11 & 40 & $78 \%$ \\
\hline zpwnrm.f & 0 & 1 & $100 \%$ & 11 & 97 & $89 \%$ \\
\hline daxpy.f & 0 & 1 & $100 \%$ & 10 & 18 & $64 \%$ \\
\hline
\end{tabular}




\begin{tabular}{|c|c|c|c|c|c|c|}
\hline dmpit.f & 0 & 1 & $100 \%$ & 10 & 111 & $91 \%$ \\
\hline dturb.f & 1 & 0 & $0 \%$ & 10 & 0 & $0 \%$ \\
\hline expand.f & 0 & 1 & $100 \%$ & 10 & 92 & $90 \%$ \\
\hline hash.f & 0 & 1 & $100 \%$ & 10 & 23 & $69 \%$ \\
\hline idamax.f & 0 & 1 & $100 \%$ & 10 & 13 & $56 \%$ \\
\hline iplen.f & 0 & 1 & $100 \%$ & 10 & 98 & $90 \%$ \\
\hline linint0.f & 0 & 1 & $100 \%$ & 10 & 55 & $84 \%$ \\
\hline mfuel.f & 0 & 1 & $100 \%$ & 10 & 22 & $68 \%$ \\
\hline mstrct.f & 0 & 1 & $100 \%$ & 10 & 56 & $84 \%$ \\
\hline pump2.f & 0 & 1 & $100 \%$ & 10 & 15 & $60 \%$ \\
\hline pumpd.f & 0 & 1 & $100 \%$ & 10 & 41 & $80 \%$ \\
\hline pumpx.f & 0 & 1 & $100 \%$ & 10 & 18 & $64 \%$ \\
\hline rerad.f & 1 & 0 & $0 \%$ & 10 & 0 & $0 \%$ \\
\hline setlcm.f & 0 & 1 & $100 \%$ & 10 & 9 & $47 \%$ \\
\hline tee2.f & 0 & 1 & $100 \%$ & 10 & 71 & $87 \%$ \\
\hline trip.f & 0 & 1 & $100 \%$ & 10 & 16 & $61 \%$ \\
\hline vssl2.f & 0 & 1 & $100 \%$ & 10 & 157 & $94 \%$ \\
\hline wtee.f & 0 & 1 & $100 \%$ & 10 & 39 & $79 \%$ \\
\hline out1d.f & 0 & 1 & $100 \%$ & 9 & 69 & $88 \%$ \\
\hline preinp.f & 0 & 1 & $100 \%$ & 9 & 213 & $95 \%$ \\
\hline prep3d.f & 0 & 1 & $100 \%$ & 9 & 121 & $93 \%$ \\
\hline sattmd.f & 0 & 1 & $100 \%$ & 9 & 7 & $43 \%$ \\
\hline sfa44v.f & 0 & 1 & $100 \%$ & 9 & 73 & $89 \%$ \\
\hline bkstb3.f & 0 & 1 & $100 \%$ & 8 & 211 & $96 \%$ \\
\hline chkbd.f & 0 & 1 & $100 \%$ & 8 & 92 & $92 \%$ \\
\hline renc.f & 0 & 1 & $100 \%$ & 8 & 96 & $92 \%$ \\
\hline repump.f & 0 & 1 & $100 \%$ & 8 & 134 & $94 \%$ \\
\hline
\end{tabular}


LA-UR-98-959

unnumb.f

vssl1.f

bits.f

chen.f

fpropd.f

locvlv.f

mfrod.f

rehtst.f

shrink.f

clrint.f

core3.f

find.f

findh.f

fwall.f

graf.f

igprzr.f

igvssl.f

iwall3.f

justlr.f

rprizr.f

tee3.f

vssl3.f

wcomp.f

wmxytb.f

delay.f

dscal.f

htstrp.f

0

1

$100 \%$

8

40

196

$100 \%$

$100 \%$

$100 \%$

$0 \%$

$100 \%$

$100 \%$

$100 \%$

$100 \%$

$100 \%$

$100 \%$

$100 \%$

$100 \%$

$100 \%$

$100 \%$

$100 \%$

$100 \%$

$100 \%$

$100 \%$

$100 \%$

$100 \%$

$100 \%$

1

0

1

1
24

35

30

19

62

7

7

7

7

7

7

76

47

0

88

17

24

121

130

41

496

153

35

35

100

143

212

88

29

18

210
$83 \%$

$96 \%$

$77 \%$

$83 \%$

$81 \%$

$73 \%$

$89 \%$

$91 \%$

$87 \%$

$0 \%$

$93 \%$

$73 \%$

$80 \%$

$95 \%$

$95 \%$

$87 \%$

$98 \%$

$96 \%$

$85 \%$

$85 \%$

$94 \%$

$95 \%$

$97 \%$

$93 \%$

$85 \%$

$78 \%$

$97 \%$ 


\section{LA-UR-98-959}

\begin{tabular}{|c|c|c|c|c|c|c|}
\hline ifset.f & 0 & 1 & $100 \%$ & 5 & 2 & $28 \%$ \\
\hline ipipe.f & 0 & 1 & $100 \%$ & 5 & 50 & $90 \%$ \\
\hline ipump.f & 0 & 1 & $100 \%$ & 5 & 55 & $91 \%$ \\
\hline j3d.f & 0 & 1 & $100 \%$ & 5 & 143 & $96 \%$ \\
\hline plen3.f & 0 & 1 & $100 \%$ & 5 & 54 & $91 \%$ \\
\hline switch.f & 1 & 0 & $0 \%$ & 5 & 0 & $0 \%$ \\
\hline tf1ds3.f & 0 & 1 & $100 \%$ & 5 & 551 & $99 \%$ \\
\hline viscvh.f & 0 & 1 & $100 \%$ & 5 & 38 & $88 \%$ \\
\hline bansol.f & 0 & 1 & $100 \%$ & 4 & 44 & $91 \%$ \\
\hline ciradh.f & 0 & 1 & $100 \%$ & 4 & 37 & $90 \%$ \\
\hline civssl.f & 0 & 1 & $100 \%$ & 4 & 60 & $93 \%$ \\
\hline cpvv1d.f & 0 & 1 & $100 \%$ & 4 & 8 & $66 \%$ \\
\hline fwkf.f & 0 & 1 & $100 \%$ & 4 & 35 & $89 \%$ \\
\hline hvwebb.f & 0 & 1 & $100 \%$ & 4 & 38 & $90 \%$ \\
\hline ibrk.f & 0 & 1 & $100 \%$ & 4 & 71 & $94 \%$ \\
\hline junsol.f & 0 & 1 & $100 \%$ & 4 & 21 & $84 \%$ \\
\hline lchpip.f & 0 & 1 & $100 \%$ & 4 & 5 & $55 \%$ \\
\hline lcmtrn.f & 0 & 1 & $100 \%$ & 4 & 32 & $88 \%$ \\
\hline movlev.f & 1 & 0 & $0 \%$ & 4 & 0 & $0 \%$ \\
\hline out3d.f & 0 & 1 & $100 \%$ & 4 & 59 & $93 \%$ \\
\hline replen.f & 0 & 1 & $100 \%$ & 4 & 94 & $95 \%$ \\
\hline rfdbk.f & 0 & 1 & $100 \%$ & 4 & 122 & $96 \%$ \\
\hline satded.f & 0 & 1 & $100 \%$ & 4 & 7 & $63 \%$ \\
\hline satprd.f & 0 & 1 & $100 \%$ & 4 & 7 & $63 \%$ \\
\hline sclmom.f & 0 & 1 & $100 \%$ & 4 & 75 & $94 \%$ \\
\hline scmlcm.f & 0 & 1 & $100 \%$ & 4 & 26 & $86 \%$ \\
\hline trips.f & 0 & 1 & $100 \%$ & 4 & 27 & $87 \%$ \\
\hline
\end{tabular}


LA-UR-98-959

\begin{tabular}{|c|c|c|c|c|c|c|}
\hline value.f & 0 & 1 & $100 \%$ & 4 & 67 & $94 \%$ \\
\hline xtvdr.f & 0 & 1 & $100 \%$ & 4 & 49 & $92 \%$ \\
\hline astpln.f & 0 & 1 & $100 \%$ & 3 & 54 & $94 \%$ \\
\hline ctain1.f & 1 & 0 & $0 \%$ & 3 & 0 & $0 \%$ \\
\hline ctain2.f & 1 & 0 & $0 \%$ & 3 & 0 & $0 \%$ \\
\hline ctain3.f & 1 & 0 & $0 \%$ & 3 & 0 & $0 \%$ \\
\hline evaldf.f & 0 & 1 & $100 \%$ & 3 & 77 & $96 \%$ \\
\hline indel.f & 0 & 1 & $100 \%$ & 3 & 18 & $85 \%$ \\
\hline jfind.f & 0 & 1 & $100 \%$ & 3 & 8 & $72 \%$ \\
\hline lchvss.f & 0 & 1 & $100 \%$ & 3 & 10 & $76 \%$ \\
\hline locpmp.f & 0 & 1 & $100 \%$ & 3 & 16 & $84 \%$ \\
\hline loctee.f & 0 & 1 & $100 \%$ & 3 & 4 & $57 \%$ \\
\hline mgap.f & 0 & 1 & $100 \%$ & 3 & 33 & $91 \%$ \\
\hline order.f & 0 & 1 & $100 \%$ & 3 & 92 & $96 \%$ \\
\hline rddim.f & 0 & 1 & $100 \%$ & 3 & 54 & $94 \%$ \\
\hline rttr.f & 0 & 1 & $100 \%$ & 3 & 18 & $85 \%$ \\
\hline sfa44.f & 0 & 1 & $100 \%$ & 3 & 72 & $96 \%$ \\
\hline sfa55.f & 0 & 1 & $100 \%$ & 3 & 114 & $97 \%$ \\
\hline split.f & 0 & 1 & $100 \%$ & 3 & 8 & $72 \%$ \\
\hline steady.f & 0 & 1 & $100 \%$ & 3 & 158 & $98 \%$ \\
\hline timstp.f & 0 & 1 & $100 \%$ & 3 & 185 & $98 \%$ \\
\hline wrcomp.f & 0 & 1 & $100 \%$ & 3 & 32 & $91 \%$ \\
\hline bfaloc.f & 0 & 1 & $100 \%$ & 2 & 15 & $88 \%$ \\
\hline chbset.f & 0 & 1 & $100 \%$ & 2 & 34 & $94 \%$ \\
\hline ciradr.f & 0 & 1 & $100 \%$ & 2 & 29 & $93 \%$ \\
\hline deltar.f & 0 & 1 & $100 \%$ & 2 & 24 & $92 \%$ \\
\hline dgbfa.f & 0 & 1 & $100 \%$ & 2 & 58 & $96 \%$ \\
\hline
\end{tabular}


LA-UR-98-959

ff3d.f

$100 \%$

123

$98 \%$

findnum.f

$100 \%$

2

10

$83 \%$

getcenc.f

$100 \%$

2

9

$81 \%$

getradm.f

$100 \%$

10

$83 \%$

igplen.f

$100 \% \quad 2$

95

$97 \%$

igsvcb.f

0

$100 \%$

2

58

$96 \%$

matsol.f

0

$100 \%$

2

86

$97 \%$

modify.f

$0 \%$

2

0

$0 \%$

nxtcmp.f

$100 \%$

16

$88 \%$

poster.f

$100 \%$

164

$98 \%$

putradm.f

$100 \%$

10

$83 \%$

rdcrds.f

$100 \%$

8

$80 \%$

recomp.f

$100 \%$

57

$96 \%$

scltbl.f

$100 \%$

21

$91 \%$

setic.f

1

$0 \%$

0

$0 \%$

sgefat.f

$100 \%$

32

$94 \%$

stbme.f

$100 \%$

376

$99 \%$

tee1x.f

$100 \%$

35

$94 \%$

vlve1.f

0

$100 \%$

25

$92 \%$

warray.f

$100 \%$

64

$96 \%$

wpipe.f

$100 \%$

42

$95 \%$

xtvinit.f

$100 \%$

119

$98 \%$

blkdat.f

$0 \%$

0

$0 \%$

blkdat2.f

$0 \%$

0

$0 \%$

fceinfo.f

1

$100 \%$

9

$90 \%$

frod.f

0

1

$100 \%$

31

$96 \%$

fthex.f

0

1

$100 \%$

7

$87 \%$ 


\begin{tabular}{|c|c|c|c|c|c|c|}
\hline getrdm1.f & 0 & 1 & $100 \%$ & 1 & 7 & $87 \%$ \\
\hline hqrt.f & 0 & 1 & $100 \%$ & 1 & 127 & $99 \%$ \\
\hline ltopp.f & 0 & 1 & $100 \%$ & 1 & 16 & $94 \%$ \\
\hline manage.f & 0 & 1 & $100 \%$ & 1 & 46 & $97 \%$ \\
\hline mzirc.f & 0 & 1 & $100 \%$ & 1 & 26 & $96 \%$ \\
\hline pipe3.f & 0 & 1 & $100 \%$ & 1 & 26 & $96 \%$ \\
\hline pntrod.f & 0 & 1 & $100 \%$ & 1 & 210 & $99 \%$ \\
\hline ptrspl.f & 0 & 1 & $100 \%$ & 1 & 43 & $97 \%$ \\
\hline pump3.f & 0 & 1 & $100 \%$ & 1 & 28 & $96 \%$ \\
\hline sfa22v.f & 0 & 1 & $100 \%$ & 1 & 16 & $94 \%$ \\
\hline teemet.f & 0 & 1 & $100 \%$ & 1 & 14 & $93 \%$ \\
\hline teemf1.f & 0 & 1 & $100 \%$ & 1 & 14 & $93 \%$ \\
\hline teemom.f & 0 & 1 & $100 \%$ & 1 & 9 & $90 \%$ \\
\hline vlve3.f & 0 & 1 & $100 \%$ & 1 & 26 & $96 \%$ \\
\hline vssrod.f & 0 & 1 & $100 \%$ & 1 & 100 & $99 \%$ \\
\hline wprizr.f & 0 & 1 & $100 \%$ & 1 & 42 & $97 \%$ \\
\hline allblk.f & 0 & 1 & $100 \%$ & 0 & 4 & $100 \%$ \\
\hline asign.f & 0 & 1 & $100 \%$ & 0 & 14 & $100 \%$ \\
\hline auxpln.f & 0 & 1 & $100 \%$ & 0 & 76 & $100 \%$ \\
\hline bacit.f & 0 & 1 & $100 \%$ & 0 & 31 & $100 \%$ \\
\hline bakup.f & 0 & 1 & $100 \%$ & 0 & 18 & $100 \%$ \\
\hline balanct.f & 0 & 1 & $100 \%$ & 0 & 79 & $100 \%$ \\
\hline bdplen.f & 0 & 1 & $100 \%$ & 0 & 71 & $100 \%$ \\
\hline bfclos.f & 0 & 1 & $100 \%$ & 0 & 11 & $100 \%$ \\
\hline bfin.f & 0 & 1 & $100 \%$ & 0 & 20 & $100 \%$ \\
\hline bfout.f & 0 & 1 & $100 \%$ & 0 & 16 & $100 \%$ \\
\hline bits.o & 1 & 4 & $80 \%$ & 0 & 0 & -- \\
\hline
\end{tabular}


LA-UR-98-959

\begin{tabular}{|c|c|c|c|c|c|c|}
\hline bkmom.f & 0 & 1 & $100 \%$ & 0 & 49 & $100 \%$ \\
\hline bksmom.f & 0 & 1 & $100 \%$ & 0 & 33 & $100 \%$ \\
\hline break2.f & 0 & 1 & $100 \%$ & 0 & 14 & $100 \%$ \\
\hline break3.f & 0 & 1 & $100 \%$ & 0 & 19 & $100 \%$ \\
\hline cbedit.f & 0 & 1 & $100 \%$ & 0 & 29 & $100 \%$ \\
\hline cdthex.f & 0 & 1 & $100 \%$ & 0 & 11 & $100 \%$ \\
\hline cella3.f & 0 & 1 & $100 \%$ & 0 & 125 & $100 \%$ \\
\hline cellav.f & 0 & 1 & $100 \%$ & 0 & 42 & $100 \%$ \\
\hline chbd.f & 0 & 1 & $100 \%$ & 0 & 14 & $100 \%$ \\
\hline chbsav.f & 0 & 1 & $100 \%$ & 0 & 12 & $100 \%$ \\
\hline $\operatorname{chf} 1 . f$ & 0 & 1 & $100 \%$ & 0 & 19 & $100 \%$ \\
\hline chksr.f & 0 & 1 & $100 \%$ & 0 & 14 & $100 \%$ \\
\hline cihtst.f & 0 & 1 & $100 \%$ & 0 & 39 & $100 \%$ \\
\hline cirad.f & 0 & 1 & $100 \%$ & 0 & 57 & $100 \%$ \\
\hline clean.f & 0 & 1 & $100 \%$ & 0 & 10 & $100 \%$ \\
\hline clear.f & 0 & 1 & $100 \%$ & 0 & 6 & $100 \%$ \\
\hline compi.f & 0 & 1 & $100 \%$ & 0 & 66 & $100 \%$ \\
\hline concf.f & 0 & 1 & $100 \%$ & 0 & 9 & $100 \%$ \\
\hline constb.f & 0 & 1 & $100 \%$ & 0 & 64 & $100 \%$ \\
\hline copya.f & 0 & 1 & $100 \%$ & 0 & 4 & $100 \%$ \\
\hline courno.f & 0 & 1 & $100 \%$ & 0 & 7 & $100 \%$ \\
\hline cpll.f & 0 & 1 & $100 \%$ & 0 & 7 & $100 \%$ \\
\hline cplld.f & 0 & 1 & $100 \%$ & 0 & 4 & $100 \%$ \\
\hline cpllh.f & 0 & 1 & $100 \%$ & 0 & 4 & $100 \%$ \\
\hline cpvv1.f & 0 & 1 & $100 \%$ & 0 & 7 & $100 \%$ \\
\hline cpvv1h.f & 0 & 1 & $100 \%$ & 0 & 12 & $100 \%$ \\
\hline cvmgt.f & 0 & 1 & $100 \%$ & 0 & 4 & $100 \%$ \\
\hline
\end{tabular}


LA-UR-98-959

cwvssl.f

$100 \%$

5

$100 \%$

cylht.o

1

$100 \%$

0

dater.f

1

$100 \%$

19

$100 \%$

dbrk.f

1

$100 \%$

9

$100 \%$

dcodf.f

1

$100 \%$

18

$100 \%$

dcomp.f

$100 \% \quad 0$

106

$100 \%$

decays.f

$100 \% \quad 0$

155

$100 \%$

dfill.f

$100 \%$

9

$100 \%$

dhtstr.f

$100 \%$

0

46

$100 \%$

dlevel.f

$100 \%$

0

\section{5}

$100 \%$

dpipe.f

$100 \%$

9

$100 \%$

dplen.f

$100 \%$

42

$100 \%$

dpump.f

$100 \%$

15

$100 \%$

drad.f

1

$100 \%$

6

$100 \%$

drod1.f

$100 \%$

115

$100 \%$

dtee.f

$100 \%$

20

$100 \%$

dvlve.f

$100 \%$

10

$100 \%$

dvpscl.f

$100 \%$

15

$100 \%$

dvssl.f

0

$100 \%$

120

$100 \%$

enddmp.f

$100 \%$

6

$100 \%$

endgrf.f

$100 \%$

6

$100 \%$

error.f

$100 \%$

48

$100 \%$

etee.f

$100 \%$

78

$100 \%$

faxpos.f

$100 \%$

39

$100 \%$

fceinf1.f

1

$100 \%$

12

$100 \%$

fill1.f

1

$100 \%$

20

$100 \%$

fill2.f

0

1

$100 \%$

3

$100 \%$ 


\section{LA-UR-98-959}

fill3.

$100 \%$

4

$100 \%$

finder.f

0

$100 \%$

23

$100 \%$

fltom.f

0

$100 \%$

52

$100 \%$

flux.f

0

$100 \%$

44

$100 \%$

fluxes.f

$100 \%$

44

$100 \%$

fnmesh.f

0

$100 \%$

111

$100 \%$

fprop.f

$100 \%$

7

$100 \%$

fproph.f 0

$100 \% \quad 0$

37

$100 \%$

gapht.f 0

$100 \% \quad 0$

16

$100 \%$

getbit.f

$100 \%$

0

$100 \%$

glevel.f

$100 \%$

0

$100 \%$

grfget.f

$100 \%$

0

$100 \%$

grfput.f

$100 \%$

0

$100 \%$

gvssl1.f

$100 \%$

0

$100 \%$

gvssl2.f

$100 \%$

0

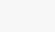

hev.f

$100 \%$

0

34

$100 \%$

hevd.f

1

$100 \%$

0

5

hevh.f

1

$100 \%$

0

5

$100 \%$

0

31

$100 \% \quad 0$

33

$100 \%$

hlfilm.f

1

$100 \% \quad 0$

47

$100 \%$

htpipe.f

1

$100 \%$

88

$100 \%$

htstr1

1

htstr3.f

1

$100 \%$

60

$100 \%$

htstrv.f

1

$100 \%$

70

18

8

$100 \%$

hunts.f

1

$100 \%$

0

$100 \%$

0

$100 \%$

0

15

$100 \%$

$100 \%$

$100 \%$

$100 \%$

hvnb.f

0

1 


\section{LA-UR-98-959}

\begin{tabular}{|c|c|c|c|c|c|c|}
\hline icmpr.f & 0 & 1 & $100 \%$ & 0 & 4 & $100 \%$ \\
\hline idel.f & 0 & 1 & $100 \%$ & 0 & 12 & $100 \%$ \\
\hline idiff.f & 0 & 1 & $100 \%$ & 0 & 3 & $100 \%$ \\
\hline ieeecvt.f & 0 & 1 & $100 \%$ & 0 & 5 & $100 \%$ \\
\hline ifill.f & 0 & 1 & $100 \%$ & 0 & 65 & $100 \%$ \\
\hline igbrak.f & 0 & 1 & $100 \%$ & 0 & 89 & $100 \%$ \\
\hline igcomp.f & 0 & 1 & $100 \%$ & 0 & 211 & $100 \%$ \\
\hline igfill.f & 0 & 1 & $100 \%$ & 0 & 83 & $100 \%$ \\
\hline ighstr.f & 0 & 1 & $100 \%$ & 0 & 195 & $100 \%$ \\
\hline igpipe.f & 0 & 1 & $100 \%$ & 0 & 49 & $100 \%$ \\
\hline igpump.f & 0 & 1 & $100 \%$ & 0 & 73 & $100 \%$ \\
\hline igtee.f & 0 & 1 & $100 \%$ & 0 & 39 & $100 \%$ \\
\hline igvlve.f & 0 & 1 & $100 \%$ & 0 & 29 & $100 \%$ \\
\hline ilevel.f & 0 & 1 & $100 \%$ & 0 & 4 & $100 \%$ \\
\hline init.f & 0 & 1 & $100 \%$ & 0 & 17 & $100 \%$ \\
\hline initbc.f & 0 & 1 & $100 \%$ & 0 & 127 & $100 \%$ \\
\hline inner.f & 0 & 1 & $100 \%$ & 0 & 34 & $100 \%$ \\
\hline ipack.f & 0 & 1 & $100 \%$ & 0 & 8 & $100 \%$ \\
\hline iprizr.f & 0 & 1 & $100 \%$ & 0 & 47 & $100 \%$ \\
\hline iprop.f & 0 & 1 & $100 \%$ & 0 & 36 & $100 \%$ \\
\hline isort.f & 0 & 1 & $100 \%$ & 0 & 18 & $100 \%$ \\
\hline iunpack.f & 0 & 1 & $100 \%$ & 0 & 8 & $100 \%$ \\
\hline j1d.f & 0 & 1 & $100 \%$ & 0 & 75 & $100 \%$ \\
\hline jbd4.f & 0 & 1 & $100 \%$ & 0 & 12 & $100 \%$ \\
\hline jvalue.f & 0 & 1 & $100 \%$ & 0 & 12 & $100 \%$ \\
\hline labeld.f & 0 & 1 & $100 \%$ & 0 & 5 & $100 \%$ \\
\hline labelh.f & 0 & 1 & $100 \%$ & 0 & 5 & $100 \%$ \\
\hline
\end{tabular}


LA-UR-98-959

\begin{tabular}{|c|c|c|c|c|c|c|}
\hline labelp.f & 0 & 1 & $100 \%$ & 0 & 7 & $100 \%$ \\
\hline ldchar.f & 0 & 1 & $100 \%$ & 0 & 3 & $100 \%$ \\
\hline lentab.f & 0 & 1 & $100 \%$ & 0 & 6 & $100 \%$ \\
\hline level.f & 0 & 1 & $100 \%$ & 0 & 10 & $100 \%$ \\
\hline leveli.f & 0 & 1 & $100 \%$ & 0 & 9 & $100 \%$ \\
\hline levelr.f & 0 & 1 & $100 \%$ & 0 & 9 & $100 \%$ \\
\hline lint4d.f & 0 & 1 & $100 \%$ & 0 & 61 & $100 \%$ \\
\hline mbn.f & 0 & 1 & $100 \%$ & 0 & 8 & $100 \%$ \\
\hline mhtr.f & 0 & 1 & $100 \%$ & 0 & 8 & $100 \%$ \\
\hline $\operatorname{mix} 3 d . f$ & 0 & 1 & $100 \%$ & 0 & 19 & $100 \%$ \\
\hline mixprp.f & 0 & 1 & $100 \%$ & 0 & 12 & $100 \%$ \\
\hline movinfo.f & 0 & 1 & $100 \%$ & 0 & 8 & $100 \%$ \\
\hline mprop.f & 0 & 1 & $100 \%$ & 0 & 11 & $100 \%$ \\
\hline newdlt.f & 0 & 1 & $100 \%$ & 0 & 137 & $100 \%$ \\
\hline orthest.f & 0 & 1 & $100 \%$ & 0 & 44 & $100 \%$ \\
\hline outer.f & 0 & 1 & $100 \%$ & 0 & 132 & $100 \%$ \\
\hline packit.f & 0 & 1 & $100 \%$ & 0 & 39 & $100 \%$ \\
\hline pipe1.f & 0 & 1 & $100 \%$ & 0 & 16 & $100 \%$ \\
\hline pipe1x.f & 0 & 1 & $100 \%$ & 0 & 20 & $100 \%$ \\
\hline pipe2.f & 0 & 1 & $100 \%$ & 0 & 12 & $100 \%$ \\
\hline piprod.f & 0 & 1 & $100 \%$ & 0 & 73 & $100 \%$ \\
\hline plen1.f & 0 & 1 & $100 \%$ & 0 & 67 & $100 \%$ \\
\hline plen2.f & 0 & 1 & $100 \%$ & 0 & 43 & $100 \%$ \\
\hline pntvss.f & 0 & 1 & $100 \%$ & 0 & 93 & $100 \%$ \\
\hline powint.f & 0 & 1 & $100 \%$ & 0 & 28 & $100 \%$ \\
\hline prep.f & 0 & 1 & $100 \%$ & 0 & 13 & $100 \%$ \\
\hline preper.f & 0 & 1 & $100 \%$ & 0 & 161 & $100 \%$ \\
\hline
\end{tabular}


LA-UR-98-959

prizr1

0

$100 \%$

0

16

$100 \%$

prizr2.f

0

1

$100 \%$

8

$100 \%$

prizr3.f

1

$100 \%$

31

$100 \%$

przr1x.f

1

$100 \%$

29

$100 \%$

pstepq.f

1

$100 \%$

28

$100 \%$

ptrsa.f

0

$100 \%$

286

$100 \%$

pump1.f

$100 \%$

0

12

$100 \%$

pumpi.f

$100 \%$

0

13

$100 \%$

putrdm1.f

$100 \%$

0

3

$100 \%$

rlmacht.f 0

$100 \%$

0

4

$100 \%$

$\begin{array}{lll}\text { radchts.f } & 0 & 1\end{array}$

$100 \%$.

12

$100 \%$

radchyd.f

$100 \%$

7

$100 \%$

radems.f

$100 \%$

6

$100 \%$

radfp.o

$100 \%$

0

radmodl.f

$100 \%$

25

$100 \%$

radpt.f

$100 \%$

83

$100 \%$

radsol.o

0

$100 \%$

0

rdcom3.f

1

$100 \%$

3

$100 \%$

rdcrvs.f

$100 \%$

80

$100 \%$

rdlcm.f

1

$100 \%$

5

$100 \%$

rdzmom.f

$100 \%$

63

$100 \%$

reecho.f

$100 \%$

86

$100 \%$

reprzr.f

$100 \%$

29

$100 \%$

rholiq.f

0

1

$100 \%$

7

$100 \%$

rlevel.f

1

$100 \%$

15

$100 \%$

rodht.o

1

$100 \%$

0

rrdlcm.f

0

1

$100 \%$

0

18

$100 \%$ 
LA-UR-98-959

\begin{tabular}{|c|c|c|c|c|c|c|}
\hline rrdlcm.o & 0 & 1 & $100 \%$ & 0 & 0 & -- \\
\hline rvslcm.f & 0 & 1 & $100 \%$ & 0 & 17 & $100 \%$ \\
\hline rvslcm.o & 0 & 1 & $100 \%$ & 0 & 0 & -- \\
\hline s1dptr.f & 0 & 1 & $100 \%$ & 0 & 214 & $100 \%$ \\
\hline satdeh.f & 0 & 1 & $100 \%$ & 0 & 19 & $100 \%$ \\
\hline satder.f & 0 & 1 & $100 \%$ & 0 & 7 & $100 \%$ \\
\hline satprh.f & 0 & 1 & $100 \%$ & 0 & 19 & $100 \%$ \\
\hline satprs.f & 0 & 1 & $100 \%$ & 0 & 7 & $100 \%$ \\
\hline sattmh.f & 0 & 1 & $100 \%$ & 0 & 25 & $100 \%$ \\
\hline sattmp.f & 0 & 1 & $100 \%$ & 0 & 7 & $100 \%$ \\
\hline savbd.f & 0 & 1 & $100 \%$ & 0 & 23 & $100 \%$ \\
\hline scputm.f & 0 & 1 & $100 \%$ & 0 & 2 & $100 \%$ \\
\hline sedit.f & 0 & 1 & $100 \%$ & 0 & 84 & $100 \%$ \\
\hline setbd.f & 0 & 1 & $100 \%$ & 0 & 8 & $100 \%$ \\
\hline setbdt.f & 0 & 1 & $100 \%$ & 0 & 17 & $100 \%$ \\
\hline seteos.f & 0 & 1 & $100 \%$ & 0 & 7 & $100 \%$ \\
\hline seterr.f & 0 & 1 & $100 \%$ & 0 & 3 & $100 \%$ \\
\hline setnet.f & 0 & 1 & $100 \%$ & 0 & 63 & $100 \%$ \\
\hline setva.f & 0 & 1 & $100 \%$ & 0 & 4 & $100 \%$ \\
\hline sgedit.f & 0 & 1 & $100 \%$ & 0 & 25 & $100 \%$ \\
\hline shift.f & 0 & 1 & $100 \%$ & 0 & 8 & $100 \%$ \\
\hline shiftb.f & 0 & 1 & $100 \%$ & 0 & 30 & $100 \%$ \\
\hline shiftr.f & 0 & 1 & $100 \%$ & 0 & 8 & $100 \%$ \\
\hline sigma.f & 0 & 1 & $100 \%$ & 0 & 4 & $100 \%$ \\
\hline ssl22v.f & 0 & 1 & $100 \%$ & 0 & 10 & $100 \%$ \\
\hline ssl44.f & 0 & 1 & $100 \%$ & 0 & 30 & $100 \%$ \\
\hline ssl44v.f & 0 & 1 & $100 \%$ & 0 & 26 & $100 \%$ \\
\hline
\end{tabular}


LA-UR-98-959

\begin{tabular}{|c|c|c|c|c|c|c|}
\hline ssl55.f & 0 & 1 & $100 \%$ & 0 & 43 & $100 \%$ \\
\hline stbmpl.f & 0 & 1 & $100 \%$ & 0 & 40 & $100 \%$ \\
\hline stdir.f & 0 & 1 & $100 \%$ & 0 & 77 & $100 \%$ \\
\hline tbc1.f & 0 & 1 & $100 \%$ & 0 & 16 & $100 \%$ \\
\hline tcputm.f & 0 & 1 & $100 \%$ & 0 & 4 & $100 \%$ \\
\hline teemf2.f & 0 & 1 & $100 \%$ & 0 & 7 & $100 \%$ \\
\hline teex.f & 0 & 1 & $100 \%$ & 0 & 23 & $100 \%$ \\
\hline tf1d.f & 0 & 1 & $100 \%$ & 0 & 58 & $100 \%$ \\
\hline tf3ds.o & 0 & 1 & $100 \%$ & 0 & 0 & -- \\
\hline tfpln.o & 0 & 1 & $100 \%$ & 0 & 0 & -- \\
\hline thcl.f & 0 & 1 & $100 \%$ & 0 & 7 & $100 \%$ \\
\hline thcld.f & 0 & 1 & $100 \%$ & 0 & 5 & $100 \%$ \\
\hline thclh.f & 0 & 1 & $100 \%$ & 0 & 6 & $100 \%$ \\
\hline thev.f & 0 & 1 & $100 \%$ & 0 & 11 & $100 \%$ \\
\hline thermo.f & 0 & 1 & $100 \%$ & 0 & 7 & $100 \%$ \\
\hline timed.f & 0 & 1 & $100 \%$ & 0 & 4 & $100 \%$ \\
\hline timupd.f & 0 & 1 & $100 \%$ & 0 & 18 & $100 \%$ \\
\hline tmpptr.f & 0 & 1 & $100 \%$ & 0 & 133 & $100 \%$ \\
\hline trac.o & 0 & 1 & $100 \%$ & 0 & 0 & -- \\
\hline trislv.f & 0 & 1 & $100 \%$ & 0 & 14 & $100 \%$ \\
\hline uncnvt.f & 0 & 1 & $100 \%$ & 0 & 70 & $100 \%$ \\
\hline vfwall3.f & 0 & 1 & $100 \%$ & 0 & 17 & $100 \%$ \\
\hline viscl.f & 0 & 1 & $100 \%$ & 0 & 7 & $100 \%$ \\
\hline viscld.f & 0 & 1 & $100 \%$ & 0 & 5 & $100 \%$ \\
\hline visclh.f & 0 & 1 & $100 \%$ & 0 & 15 & $100 \%$ \\
\hline viscv.f & 0 & 1 & $100 \%$ & 0 & 7 & $100 \%$ \\
\hline vlve2.f & 0 & 1 & $100 \%$ & 0 & 10 & $100 \%$ \\
\hline
\end{tabular}


LA-UR-98-959

\begin{tabular}{|c|c|c|c|c|c|c|}
\hline vmcell.f & 0 & 1 & $100 \%$ & 0 & 5 & $100 \%$ \\
\hline volv.f & 0 & 1 & $100 \%$ & 0 & 16 & $100 \%$ \\
\hline vpoint.f & 0 & 1 & $100 \%$ & 0 & 295 & $100 \%$ \\
\hline vrbd.f & 0 & 1 & $100 \%$ & 0 & 31 & $100 \%$ \\
\hline wand.f & 0 & 1 & $100 \%$ & 0 & 5 & $100 \%$ \\
\hline wdrag.f & 0 & 1 & $100 \%$ & 0 & 21 & $100 \%$ \\
\hline wfill.f & 0 & 1 & $100 \%$ & 0 & 16 & $100 \%$ \\
\hline whtstr.f & 0 & 1 & $100 \%$ & 0 & 392 & $100 \%$ \\
\hline wiarr.f & 0 & 1 & $100 \%$ & 0 & 12 & $100 \%$ \\
\hline wjcell.f & 0 & 1 & $100 \%$ & 0 & 4 & $100 \%$ \\
\hline wlabi.f & 0 & 1 & $100 \%$ & 0 & 38 & $100 \%$ \\
\hline wlabr.f & 0 & 1 & $100 \%$ & 0 & 42 & $100 \%$ \\
\hline wlevel.f & 0 & 1 & $100 \%$ & 0 & 14 & $100 \%$ \\
\hline wor.f & 0 & 1 & $100 \%$ & 0 & 5 & $100 \%$ \\
\hline wplen.f & 0 & 1 & $100 \%$ & 0 & 89 & $100 \%$ \\
\hline wpump.f & 0 & 1 & $100 \%$ & 0 & 49 & $100 \%$ \\
\hline wrlcm.f & 0 & 1 & $100 \%$ & 0 & 5 & $100 \%$ \\
\hline wvlve.f & 0 & 1 & $100 \%$ & 0 & 40 & $100 \%$ \\
\hline wvssl.f & 0 & 1 & $100 \%$ & 0 & 170 & $100 \%$ \\
\hline wxor.f & 0 & 1 & $100 \%$ & 0 & 5 & $100 \%$ \\
\hline xtv1d.f & 0 & 1 & $100 \%$ & 0 & 30 & $100 \%$ \\
\hline xtvbi3e.f & 0 & 1 & $100 \%$ & 0 & 3 & $100 \%$ \\
\hline xtvbuf.f & 0 & 1 & $100 \%$ & 0 & 26 & $100 \%$ \\
\hline$x t v c b . f$ & 0 & 1 & $100 \%$ & 0 & 23 & $100 \%$ \\
\hline xtvht.f & 0 & 1 & $100 \%$ & 0 & 68 & $100 \%$ \\
\hline xtvpipe.f & 0 & 1 & $100 \%$ & 0 & 9 & $100 \%$ \\
\hline xtvplen.f & 0 & 1 & $100 \%$ & 0 & 28 & $100 \%$ \\
\hline
\end{tabular}




\section{LA-UR-98-959}

$\begin{array}{lllllll}\text { xtvpump.f } & 0 & 1 & 100 \% & 0 & 9 & 100 \% \\ \text { xtvsig.f } & 0 & 1 & 100 \% & 0 & 21 & 100 \% \\ \text { xtvtee.f } & 0 & 1 & 100 \% & 0 & 9 & 100 \% \\ \text { xtvvalv.f } & 0 & 1 & 100 \% & 0 & 9 & 100 \% \\ \text { xtvvsl.f } & 0 & 1 & 100 \% & 0 & 62 & 100 \% \\ \text { zerov.f } & 0 & 1 & 100 \% & 0 & 32 & 100 \% \\ \text { zpwhci.f } & 0 & 1 & 100 \% & 0 & 57 & 100 \%\end{array}$

